Portland State University

PDXScholar

5-6-1993

\title{
Quasi-Static Deflection Compensation Control of Flexible Manipulator
}

Jingbin Feng

Portland State University

Follow this and additional works at: https://pdxscholar.library.pdx.edu/open_access_etds

Part of the Mechanical Engineering Commons

Let us know how access to this document benefits you.

\section{Recommended Citation}

Feng, Jingbin, "Quasi-Static Deflection Compensation Control of Flexible Manipulator" (1993).

Dissertations and Theses. Paper 4759.

https://doi.org/10.15760/etd.6643

This Thesis is brought to you for free and open access. It has been accepted for inclusion in Dissertations and Theses by an authorized administrator of PDXScholar. Please contact us if we can make this document more accessible: pdxscholar@pdx.edu. 
AN ABSTRACT OF THE THESIS OF Jingbin Feng for the Master of Science in Mechanical Engineering presented May 6, 1993.

Title: Quasi-Static Deflection Compensation Control of Flexible Manipulator.

APPROVED BY THE MEMBERS OF THE THESIS COMMITTEE:

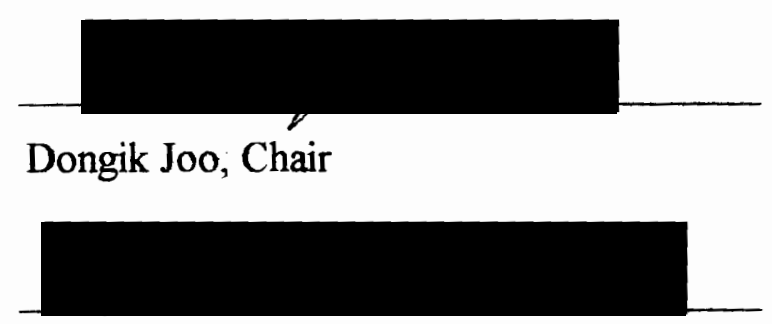

David A. Turcic

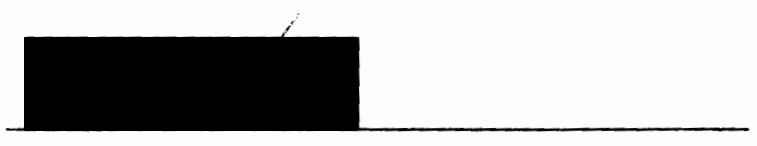

Gerardo. Lafferriere

The growing need in industrial applications of high-performance robots has led to designs of lightweight robot arms. However the light-weight robot arm introduces accuracy and vibration problems. The classical robot design and control method based on the rigid body assumption is no longer satisfactory for the light-weight manipulators. The effects of flexibility of light-weight manipulators have been an active research area in recent years. 
A new approach to correct the quasi-static position and orientation error of the end-effector of a manipulator with flexible links is studied in this project. In this approach, strain gages are used to monitor the elastic reactions of the flexible links due to the weight of the manipulator and the payload in real time, the errors are then compensated on-line by a control algorithm. Although this approach is designed to work for general loading conditions, only the bending deflection in a plane is investigated in detail. It is found that minimum,two strain gages per link are needed to monitor the deflection of a robot arm subjected to bending. A mathematical model relating the deflections and strains is developed using Castigliano's theorem of least work. The parameters of the governing equations are obtained using the identification method. With the identification method, the geometric details of the robot arms and the carrying load need not be known. The deflections monitored by strain gages are fedback to the kinematic model of the manipulator to find the position and orientation of the end-effector of the manipulator. A control algorithm is developed to compensate the deflections. The inverse kinematics that includes deflections as variables is solved in closed form. If the deflections at target position are known, this inverse kinematics will generate the exact joint command for the flexible manipulator. However the deflections of the robot arms at the target position are unknown ahead of time, the current deflections at each sampling time are used to predict the deflections at target position and the joint command is modified until the required accuracy is obtained.

An experiment is set up to verify the mathematical model relating the strains to the deflections. The results of the experiment show good agreement with the model. The 
compensation control algorithm is first simulated in a computer program. The simulation also shows good convergence. An experimental manipulator with two flexible links is built to prove this approach. The experimental results show that this compensation control improves the position accuracy of the flexible manipulator significantly. The following are the brief advantages of this approach: the deflections can be monitored without measuring the payload directly and without the detailed knowledge of link geometry; the manipulator calibrates itself with minimum human intervention; the compensation control algorithm can be easily integrated with the existing uncompensated rigid-body algorithm; it is inexpensive and practical for implementation to manipulators installed in workplaces. 


\title{
QUASI-STATIC DEFLECTION COMPENSATION CONTROL OF FLEXIBLE MANIPULATOR
}

\author{
by
}

JINGBIN FENG

A thesis submitted in partial fulfillment of the requirements for the degree of

\author{
MASTER OF SCIENCE \\ in \\ MECHANICAL ENGINEERING
}

Portland State University

1993 


\section{TO THE OFFICE OF GRADUATE STUDIES:}

The members of the Committee approve the thesis of Jingbin Feng presented May

6, 1993.

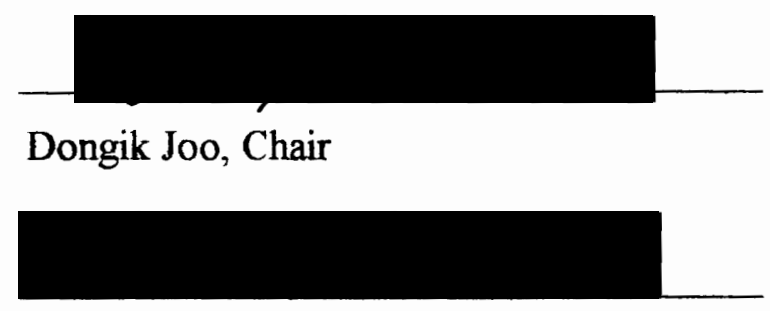

David A. Turcic

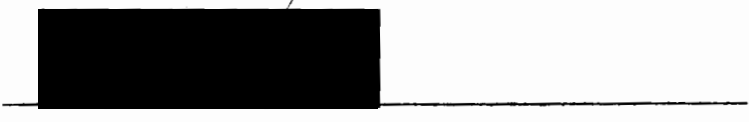

Gerardo. Lafferriere

APPROVED:

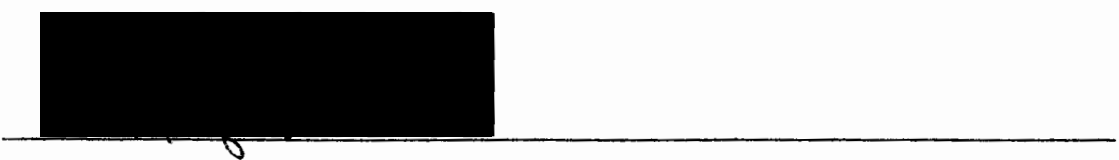

Graig Spolek, Chair, Department of Mechanical Engineering

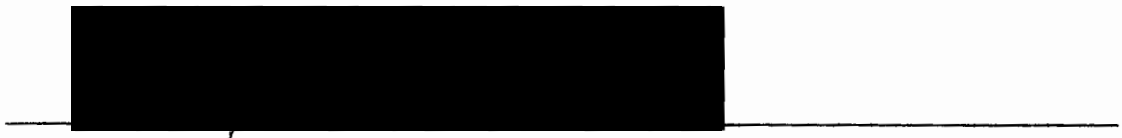

Roy W. Koch, Vice Provost for Graduate Studies and Research 


\section{ACKNOWLEDGEMENTS}

I wish to express my sincere gratitude to all the members of my thesis committee for their advice. I particularly wish to thank my advisor, Dr. Dongik Joo for his guidance and encouragement throughout the research. I wish to thank Dr. David A. Turcic for his willingness to give me advice. I wish to thank Mr. Griffin John for his help during the experiment. Finally, but foremost, I wish to thank my wife for her spiritual support. 
TABLE OF CONTENTS

PAGE

ACKNOWLEDGEMENTS $\ldots \ldots \ldots \ldots \ldots \ldots \ldots \ldots$ iii

LIST OF TABLES $\ldots \ldots \ldots \ldots \ldots \ldots \ldots \ldots \ldots \ldots \ldots \ldots \ldots \ldots$ vii

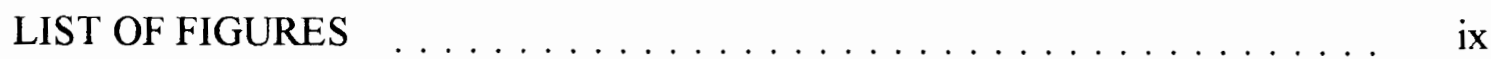

CHAPTER

I INTRODUCTION $\ldots \ldots \ldots \ldots \ldots \ldots \ldots \ldots \ldots$

II DEFLECTION MODELING OF MANIPULATOR LINKS _ . 6

II.1 Introduction $\ldots \ldots \ldots \ldots \ldots \ldots \ldots \ldots \ldots$

II.2 Links Under Payloads $\ldots \ldots \ldots \ldots \ldots \ldots \ldots \ldots$

II.3 A Variational Method Based on CTLW . . . . . . 8

II.4 Relation Between Strain and Deflection $\ldots \ldots \ldots \ldots \quad 9$

II.5 Discussion of Constant $Z$ s $\ldots \ldots \ldots \ldots \ldots \ldots \ldots \ldots$

III EXPERIMENTAL VERIFICATION OF

DEFLECTION MODEL $\ldots \ldots \ldots \ldots \ldots \ldots \ldots$

III.1 Introduction $\ldots \ldots \ldots \ldots \ldots \ldots \ldots \ldots \ldots \ldots$

III.2 Experimental Setup $\ldots \ldots \ldots \ldots \ldots \ldots \ldots \ldots$ 
PAGE

III.3 Strain and Deflection Measurements . . . . . . . . . . . 19

III.4 An Experiment on An Aluminum Bar f . . . . . . . 20

III.5 An Experiment on A Composite Hollow Cylinder . . . . . 22

IV CONTROL ALGORITHM $\ldots \ldots \ldots \ldots \ldots \ldots \ldots$

IV.1 Introduction $\ldots \ldots \ldots \ldots \ldots \ldots \ldots \ldots \ldots \ldots \ldots \ldots$

IV.2 Kinematic Analysis $\ldots \ldots \ldots \ldots \ldots \ldots \ldots \ldots \ldots$

IV.3 An Example of Kinematic Model for A

Planar Manipulator with Three Flexible Links . . . . . . . 31

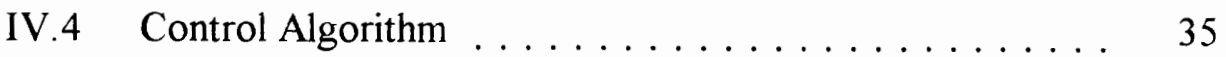

V COMPUTER SIMULATION $\ldots \ldots \ldots \ldots \ldots \ldots \ldots$

V.1 Introduction $\ldots \ldots \ldots \ldots \ldots \ldots \ldots$

V.2 Description of The Simulation Program ... . . . . . 38

V.3 Simulations ...................4 40

VI EXPERIMENT ON A MANIPULATOR

WITH TWO FLEXIBLE LINKS . . . . . . . . . . . . . 46

VI.1 Introduction $\ldots \ldots \ldots \ldots \ldots \ldots \ldots \ldots \ldots$

V1.2 The Experimental Manipulator . . . . . . . . . . . . 46

VI.3 Path Planning of The Joint Angles f. . . . . . . . . 54

VI.4 Experiment on Joint Space Control . . . . . . . . . . . 56 
PAGE

\section{VI.5 Experiment on Deflection}

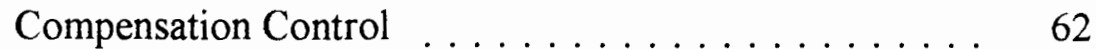

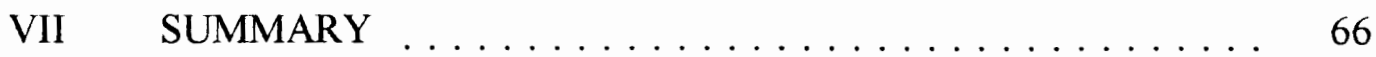

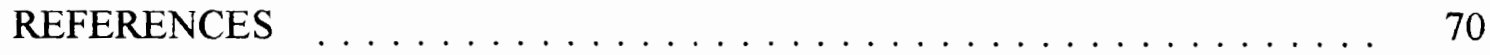




\section{LIST OF TABLES}

TABLE

PAGE

I Physical Parameters for the Aluminum Bar

II Identification Data for the Aluminum Bar

V Identification Data for the Composite Beam

VIII Parameters and Variables for the Manipulator with Three Flexible Links

IX Parameters of the Manipulator for Simulation $\ldots \ldots \ldots \ldots \ldots$

$\mathrm{X} \quad$ Results for the Simulation in Point-to-point Mode with $10 \mathrm{lb}$ Payload

XI Results for the Simulation in Point-to-point Mode with 20 lb Payload

XII Parameters of Link \#1 of the Experimental Manipulator . . . . . 


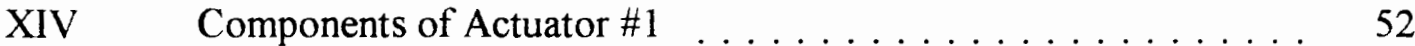

XV Components of Actuator \#2 $\ldots \ldots \ldots \ldots \ldots \ldots \ldots$

XVI Data Acquisition and Control Hardware $\ldots \ldots \ldots \ldots \ldots 4$

XVII Experimental Result on The Two-link Manipulator for Point \#1 64

XVIII Experimental Result on The Two-link Manipulator for Point \#2 64

XIX Experimental Result on The Two-link Manipulator for Point \#3 64

XX Experimental Result on The Two-link Manipulator for Point \#4 65 


\section{LIST OF FIGURES}

FIGURE

PAGE

$1 \quad$ Bending Deflection $\ldots \ldots \ldots \ldots \ldots \ldots \ldots \ldots \ldots$

2 Torsional Deflection $\ldots \ldots \ldots \ldots \ldots \ldots \ldots \ldots$

$3 \quad$ Axial Deflection $\ldots \ldots \ldots \ldots \ldots \ldots \ldots$

$4 \quad$ A Link under Bending $\ldots \ldots \ldots \ldots \ldots \ldots \ldots \ldots \ldots \ldots \ldots \ldots$

5 Experimental Setup for the Verification of Strain-deflection Model $\ldots \ldots \ldots \ldots 17$

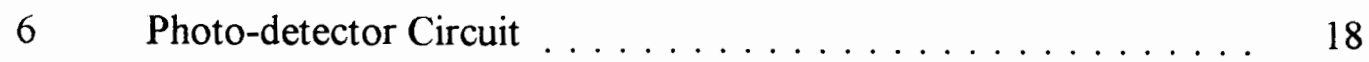

7 Wheatstone Bridge Completion $\ldots \ldots \ldots \ldots \ldots \ldots \ldots \ldots \ldots \ldots$

$8 \quad$ Loading Configuration $\ldots \ldots \ldots \ldots \ldots \ldots \ldots \ldots \ldots$

9 Experimental Result for Composite Beam, Loading Group \#1 . . 26

10 Coordinate System for Rigid Manipulator . . . . . . . . . . . . 29

11 Coordinate System for Flexible Manipulator f... . . . . . 30

12 Kinematics for A Manipulator with Three Flexible Links . . . . . 32

13 Flow Chart of Deflection Compensation Control ... . . . . 37

14 Screen of Simulation Program $\ldots \ldots \ldots \ldots \ldots \ldots$

15 Configuration of Simulation in Point-to-point Mode . . . . . . . 42 
16 Computer Simulation Results in Path Mode . . . . . . . . . . . . 45

17 Experimental Manipulator $\ldots \ldots \ldots \ldots \ldots \ldots$

18 Schematic of the Experimental Manipulator $\ldots \ldots \ldots 48$

19 Functional Diagram of the Actuator control . . . . . . . . . . 51

20 Joint Trajectory Planning with Cubic Polynomial _. . . . . . . 57

$21 \quad$ Experimental Results of Joint Space Control

for Joint \#1 at Gain=2, 16, $32 \ldots \ldots \ldots 58$

22 Experimental Results of Joint Space Control

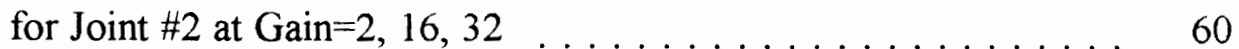

23 Experimental Results of Joint Space Control

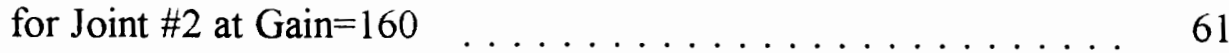

24 Experiments on the Two-link Manipulator ........... 63 


\section{CHAPTER I}

\section{INTRODUCTION}

The rapidly expanding applications of industrial robots bring to industries many benefits, including increased productivity, improved product quality and flexibility. The classical robot design is based on rigid body assumption. It oversizes the cross section of each link to make the rigid body assumption valid. In order to meet the demands of high productivity, the designers face the challenge of increased speed, increased payload, and increased accuracy of robot manipulator. The lightweight manipulator design reduces the inertia of the arms and the driving torque hence uses smaller actuators and lowers the energy consumption. Lygouras described the advantages of light-weight arm [1]. However, the lighter manipulators are more likely to deform due to the bending and torsion effects hereby reducing the accuracy and stability. The robotic manipulators, as open-loop mechanical chains, are particularly sensitive to the elastic effects of their links. The position of the end-effector is very difficult to control in the positioning task. The rigid body assumption is no longer satisfactory for lightweight manipulator design.

Hence, in the past years there has been increasing interest in the effects of structural flexibility of a manipulator on its static and dynamic performances. While much

research have been done on the mathematical modeling and experiments that involve vibration and stability control of flexible manipulator arms, a few investigations have been 
conducted on the quasi-static deflection effects at the end-effector due to changing payload and changing configuration. The static deflection effects are directly related to the accuracy of the end-effector of a manipulator, requiring an efficient and effective compensation methodology.

The methods to compensate the deflections of manipulator links can be divided into two categories. The first is to measure the position and the orientation of the end-effector directly by some external devices operated independently of the manipulator and the deflections are compensated by modifying the commands to the joint actuators. This method can eliminate the errors introduced by inaccurate modeling of flexible links. Many of these end-point measuring systems have been investigated, such as calibration fixtures with precise points, special apparatuses, external position measurement with theodolites [2,3], or an Optical system with laser-detector [4]. These systems however are difficult to use in the workplaces where the robots are installed since these systems should be calibrated precisely in laboratories [5].

In the second category, the deflections of the flexible links are calculated using some mathematical models, then a kinematic model is used to calibrate the control system to compensate the deflections. Most previous works in this category require that the exact payloads and dimensions of the links must be known ahead to calculate the deflections $[6,7]$. This is very difficult in the real applications where the manipulator links have complex shapes and the payloads vary from task to task.

Many theories have been used to calculate the deflection of the flexible links. Finite Element Method has been utilized by many researchers to model the deflections of the 
flexible manipulator links $[7,8,9]$. Kanoh described the applications of Timoshenko beam theory and Bernoulli-Euler beam theory to the flexible links [10]. Ali Meghdari described a technique to model flexible links based on Castigliano's theorem of least work (CTLW) [6]. He considers the entire serial chain of the flexible links as a whole structure, then CTLW is applied to determine the deformation of the whole structure.

To model the kinematics of a robot manipulator, homogeneous transformation is used. The $4 * 4$ Hartenberg-Denavit transformation matrices completely describe the kinematics of a manipulator with rigid links [11]. Because of the convenience of using the Hartenberg-Denavit matrix, many researchers have extended this technique to describe the kinematics of manipulator with flexible links. Chang and Hamilton proposed an Equivalent Rigid Link System (ERLS) model to describe the kinematics of robot manipulators with flexible links [8]. Yao introduced a deviation matrix to the kinematic model of the manipulator with flexible links [12]. The deviation matrix is a function of error of possible error sources (here the deflection of the flexible links). The elements of the deviation matrix are derived from the deflection model of the flexible links.

An iterative method based on the $4 * 4$ transformation matrix is presented by William and Turcic to solve the set of joint variables for the desired position and orientation of the end-effector for a flexible manipulator [9]. The deflections are assumed to be zeros first to determine the nominal configuration for the purpose of determining the deflections. The deflections of individual links then are calculated based on the finite element method and used for the iteration to obtain the desired joint angles. 
The objective of the study presented is to establish a practical method to accurately model and control a manipulator with flexible links subjected to a static payload. The deflections of the manipulator links are configuration dependable. The deflections must be detected in order to control the position of the end-effector accurately. A technique to detect the deflection in real-time using strain gages is developed systematically. The method will be verified both by computer simulation and experiment.

A flexible manipulator link is generally subjected to bending, torsional and axial deflections under its own weight and payload. As a first step, only the bending deflection in a vertical plane is investigated. To detect the deflections in real-time, strain gages are employed. A mathematical model describing the relation between the strains and the defection is developed in Chapter II. Since its generality and simplicity, Castigliano's theorem of least work (CTLW) is used to derive the relationship between the deflections and the strains. The constants in this model can be obtained using the mathematical formulas for links with simple geometry and known elastic property and can be obtained using the experimental identification method for the links with complex geometry and unknown elastic property. It is found that minimum two strain gages per link are needed to monitor the bending deflections in a plane. The advantages of using this technique to monitor the deflection over other techniques are: 1)the deflection can be monitored without knowing the geometry and elastic property of the link and 2)the deflection can be monitored without knowing the payload. Chapter III describes the experimental verification of this technique. 
To control the position and orientation of the end-effector, the deflections of the flexible links must be included in the kinematic model of the manipulator. A kinematic model which includes the deflections as variables is presented in Chapter IV. With the kinematic model including the deflections and the real-time deflection detection technique, a control algorithm is developed in Chapter IV to compensate the error of the end-effector due to structural deflections. This deflection compensation control algorithm is simulated in a computer. The simulation technique and the simulation results are presented in Chapter V.

In Chapter VI, the experimental investigation for the deflection compensation control developed in the previous chapters is presented. An experimental manipulator with two flexible links is built for the purpose of the experimental verification. The two actuators are mounted directly at the joints. The two degrees-of-freedom manipulator moves in a vertical plane and is controlled by a computer through several interfaces. The control algorithm based on the rigid-body assumption and the compensation control algorithm are used to control the manipulator. The results are compared.

Chapter VII presents a summary of the main features of this study. Then recommendations for future investigation on this approach are made . 


\section{CHAPTER II}

\section{DEFLECTION MODELING OF MANIPULATOR LINKS}

\section{1 INTRODUCTION}

A manipulator link deflects under its own weight and payloads. The deflection information is needed to describe the position and orientation of the end-effector of a flexible manipulator. This chapter presents a technique to detect the deflections of an individual flexible link. The quasi-static condition and small deflection are assumed. The dynamic loading will not be investigated in this stage of the study.

In order to monitor the deflection of a manipulator link in real-time, strain gages are used to measure the strains at some points of the link. The mathematical formulas relating the strains to the deflections due to bending in a plane will be presented in detail. The mathematical model will be derived using a variational method based on Castigliano's theorem of least work (CTLW) [6]. It will be shown that minimum two strain gages per link are needed to monitor deflections subjected to bending in a plane. Once the deflections of each link are determined, they are used for the kinematic model to compensate the inaccuracy caused by structural deflections. 


\section{2 LINKS UNDER PAYLOADS}

To model the deflection, the different loading conditions causing the deflection are analyzed. The loading conditions of a manipulator link have been described by Yao [12]. In general, a link is subjected to three different loading conditions: bending, torsion and axial loading. The bending deflection is caused by the moment Mo, transverse load Ft and its own weight $\mathrm{G}$ and it is described by transverse deflection $\Delta \mathrm{Lt}$ and angular deflection $\delta \theta$ as shown in Figure 1. The torsional deflection is caused by torsional torque $\mathrm{T}$ and it is described by torsional angle $\phi$ as shown in Figure 2. The axial deflection is cause by axial force $\mathrm{Fa}$ and it is described by axial displacement $\Delta \mathrm{La}$ as shown in Figure 3.

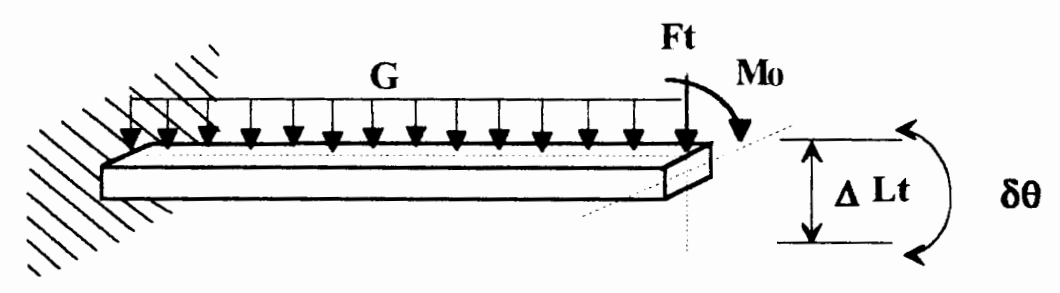

Figure 1. Bending Deflection.

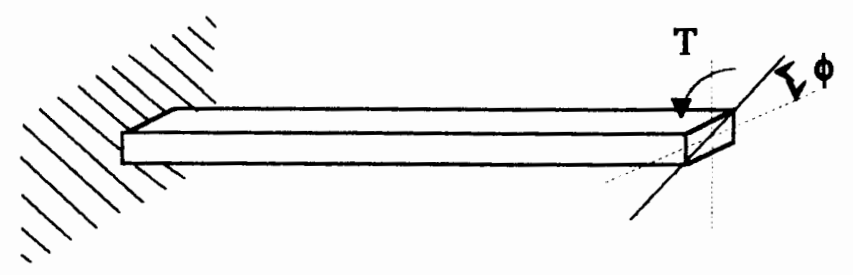

Figure 2. Torsional Deflection. 


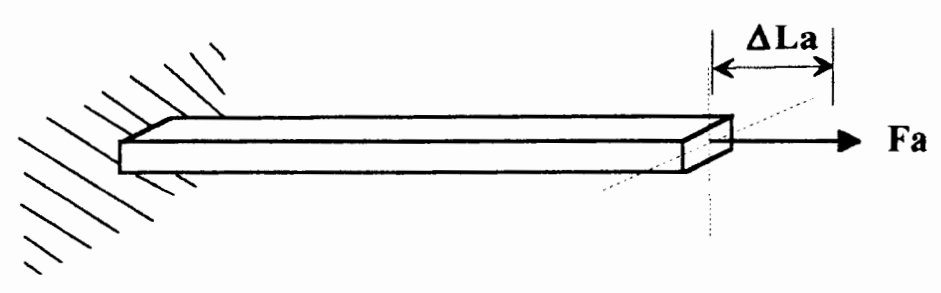

Figure 3. Axial Deflection.

The magnitude of axial bending deflection is relatively small compared with the torsional and bending deflections in manipulator applications, hence the axial deflection is neglected in most of previous research $[5,6,12]$. Only the bending deflection in a plane is investigated in this project. However the same technique will apply to other deflections.

\section{II.3 A VARIATIONAL METHOD BASED ON CTLW}

The Castigliano's theorem of least work has been applied to calculated the deflections of manipulator links by A. Meghdari [9]. Because of its generality and compatibility, the Castigliano's theorem of least work is particularly useful for studying the deflection of manipulator link. If the small deflection is assumed, the fundamental form of the Castigliano's theorem is shown in equation (2.1).

$$
q^{i}=\frac{\partial U_{c}\left(P_{i}\right)}{\partial P_{i}} \quad i=1,2, \ldots, N
$$

where $U_{c}\left(P_{i}\right)$ is the gross complementary energy of the deformable system expressed in terms of an independent set of generalized concentrated force $P_{i} ; q^{i}$ is the corresponding 
generalized deflection from natural state to the load equilibrium state corresponding to the generalized force $P_{i}$ at the particular point of the continuum, on which $P_{i}$ acts. If the defection is angular, then the generalized force is a couple applied at that ponit.

For linearly elastic structure, The complementary energy $U_{c}$ is equivalent to the gross strain energy $U_{s}$, and Castigliano's theorem will be expressed as equation (2.2).

$$
q^{i}=\frac{\partial U_{s}}{\partial P_{i}} \quad i=1,2, \ldots, N
$$

Assuming the linear superposition holds, the strain energy relation for a link subjected to bending and torsion is shown in equation (2.3).

$$
U_{s}=\frac{1}{2} \times \int_{L}\left[\frac{M^{2}}{E(l)}+\frac{T^{2}}{K}\right] \times d l
$$

where $\mathrm{M}$ is bending moment; $\mathrm{EI}$ is bending stiffness; $\mathrm{T}$ is torque; $\mathrm{K}$ is torsional stiffness.

\section{II.4 RELATION BETWEEN STAIN AND DEFLECTION}

To monitor the deflection using strain gages, a mathematical model relating strains and deflections should be formulated. For a manipulator link subjected to bending in a plane, the external payloads causing the bending deflection are transverse force $\mathrm{Ft}$ and a couple Mo acting at the end of the link as shown in Figure 2.4. These transverse force and the couple can be measured indirectly by measuring two bending strains at different 
locations on the link. With the knowledge of the external payloads, the geometry of the link and the elastic properties of the link, the defection can be determined as follows

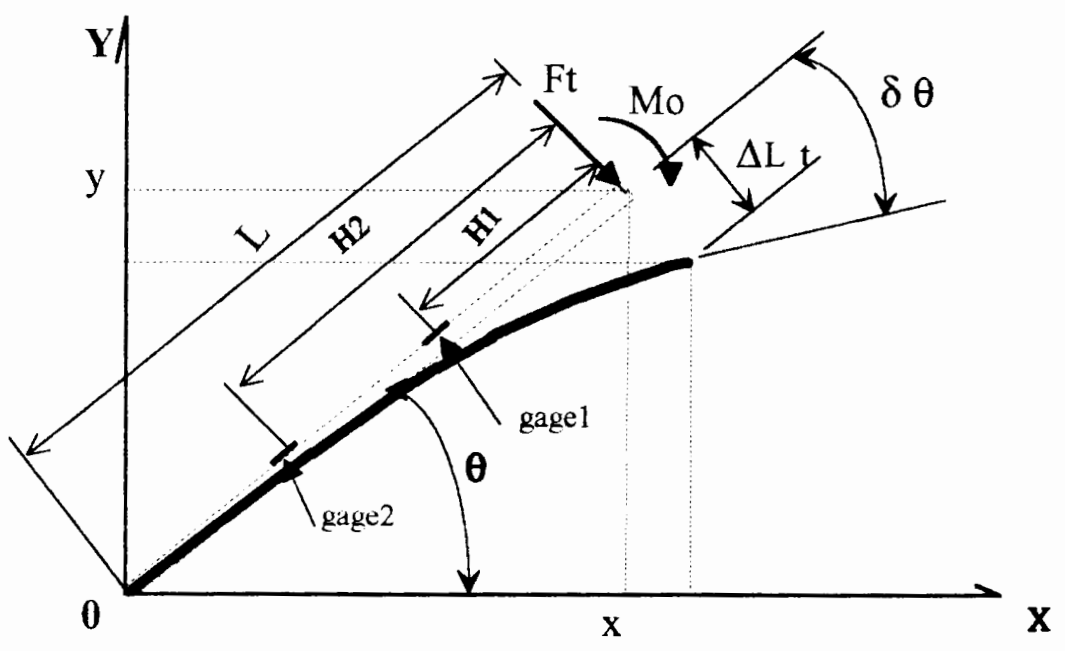

Figure 4. A Link under Bending.

The Castigliano's theorem of least work when applied to determine the bending deflection can be expressed as equations (2.4) and (2.5).

$$
\begin{aligned}
& \Delta L t=\int_{0}^{L} \frac{M(l)}{E I(l)} \times \frac{\partial M(l)}{\partial F t} \times d l \\
& \delta \theta=\int_{0}^{L} \frac{M(l)}{E I(l)} \times \frac{\partial M(l)}{\partial M_{0}} \times d l
\end{aligned}
$$

where

$\Delta \mathrm{Lt}$ is the transverse linear deflection;

$\delta \theta$ is the angular deflection; 
$L$ is the length of the link;

$M(1)$ is the bending moment along the link from the free end;

EI(l) is bending stiffness along the link from the free end;

Ft: Transverse Force;

Mo: Moment acing at the end of the link.

The bending moment at location 1 from the free end can be expressed as equation (2.6)

$$
M(l)=-F t \times l-M o-\cos \theta \times \int_{0}^{l} G(t) \times(l-t) \times d t
$$

where

$G(t)$ is the unit length mass along the link from the free end;

$\theta$ is the angle between the link and $\mathrm{X}$ axis as shown in Figure 4.

Substituting (2.6) into (2.4) and (2.5), the transverse deflection $\Delta \mathrm{Lt}$ and the angular deflection can be expressed as equations (2.7) and (2.8).

$$
\begin{aligned}
& \Delta L t=\int_{0}^{L} \frac{\left[-F\left[x-M o-\cos \theta \times \int_{0}^{l}(\dot{r}(t) \times(l-t) \times d t]\right.\right.}{E[(t)} \times(-l) \times d l \\
& =F t \times \int_{0}^{L} \frac{l^{2}}{E I(l)} \times d l+M_{o} \times \int_{0}^{L} \frac{l}{E I(l)} \times d l+\cos \theta \times \int_{0}^{L} \frac{l}{E I(l)} \times\left[\int_{0}^{l} G(t) \times(l-t) \times d t\right] \times d l \\
& \delta \theta=\int_{0}^{L} \frac{\left[-F|x|-M o-\cos \theta \int_{0}^{l} G(t) \times(l-t) \times d t\right]}{E I(t)}(-1) \times d l \\
& =F t \times \int_{0}^{L} \frac{1}{E I(l)} \times d l+M_{o} \times \int_{0}^{L} \frac{1}{E I(l)} \times d l+\cos \theta \times \int_{0}^{L} \frac{1}{E I(l)} \times\left[\int_{0}^{l} G(t) \times(l-t) \times d t\right] \times d l
\end{aligned}
$$


The bending moments $\mathrm{M} 1$ and M2 at the locations $\mathrm{H} 1$ and $\mathrm{H} 2$ (Figure 4) can be expressed as equations (2.9) and (2.10).

$$
\begin{aligned}
& M 1=-F t \times H 1-M o-\cos \theta \times \int_{0}^{H 1} G(t) \times(H 1-t) \times d t \\
& M 2=-F t \times H 2-M o-\cos \theta \times \int_{0}^{H 2} G(t) \times(H 2-t) \times d t
\end{aligned}
$$

The bending strains $\varepsilon 1$ and $\varepsilon 2$ at the locations $\mathrm{H} 1$ and $\mathrm{H} 2$ (figure 2.4) can be expressed as equations (2.11) and (2.12).

$$
\begin{aligned}
& \varepsilon 1=-\frac{M 1 \times U 1}{E I 1} \\
& \varepsilon 2=-\frac{M 2 \times U 2}{E I 2}
\end{aligned}
$$

where

EIl is the bending stiffness at the location where the strain gagel is installed;

EI2 is the bending stiffness at the location where the strain gage 2 is installed;

$\mathrm{U} 1$ is the distance between the neutral surface of the link and the point where strain gagel is installed;

$\mathrm{U} 2$ is the distance between the neutral surface of the link and the point where strain gage2 is installed.

The external payloads Ft and Mo are solved as functions of $\varepsilon 1$ and $\varepsilon 2$ using equations (2.9), (2.10), (2.11) and (2.12):

$$
F t=\frac{E I 1}{L^{\prime} 1 \times(H 1-H 2)} \times \varepsilon 1-\frac{E I 2}{U 2 \times(H 1-H 2)} \times \varepsilon 2-\frac{\cos \theta \times\left[\int_{0}^{H 1} G(t) \times(H 1-t) \times d t-\int_{0}^{H 2} G(t) \times(H 2-t) \times d t\right]}{(H 1-H 2)}
$$




$$
M_{o}=-\frac{E I 1 \times I 2}{U 1 \times(H 1-H 2)} \times \varepsilon 1+\frac{E I 2 \times I 1}{U 2 \times(H 1-H 2)} \times \varepsilon 2+\frac{\cos \theta \times\left[H 2 \times \int_{0}^{H 1} G(t) \times(H 1-t) \times d t-H 1 \times \int_{0}^{H 2} G(t) \times(H 2-t) \times d t\right]}{(H 1-H 2)}
$$

Substituting (2.13) and (2.14) into (2.7) and (2.8), the equations relating the strains to deflections are obtained as equations (2.15) and (2.16).

$$
\begin{aligned}
& \Delta L t=Z 1 \times \varepsilon 1+Z 2 \times \varepsilon 2+Z 3 \times \cos \theta \\
& \delta \theta=Z 4 \times \varepsilon 2+Z 5 \times \varepsilon 2+Z 6 \times \cos \theta
\end{aligned}
$$

where

$$
\begin{aligned}
& Z 1=\frac{E l 1}{U 1 \times(H 1-H 2)} \times\left[\int_{0}^{L} \frac{l^{2}}{E I l(l)} \times d l-H 2 \times \int_{0}^{L} \frac{l}{E I(l)} \times d I\right] \\
& Z 2=\frac{E I 2}{U 2 \times(H 1-H 2)} \times\left[H 1 \times \int_{0}^{L} \frac{l}{E I(l)} \times d l-\int_{0}^{L} \frac{l^{2}}{E I(l)} \times d l\right] \\
& Z 3=\frac{\int_{0}^{H 1} G(t) \times(H 1-t) \times d t \times\left[-\int_{0}^{L} \frac{t^{2}}{E(t)} \times d l+H 2 \times \int_{0}^{L} \frac{1}{E(t)} \times d l\right]+\int_{0}^{H 2} G(t) \times(H 2-t) \times d\left[\left[\int_{0}^{L} \frac{t^{2}}{E(t)} \times d l-H 1 \times \int_{0}^{L} \frac{1}{E(l)} \times d l\right]\right.}{(H 1-H 2)} \\
& +\int_{0}^{L} \frac{l}{E I(l)} \times\left[\int_{0}^{l} G(t) \times(l-t) \times d t\right] \times d l \\
& Z 4=\frac{E I 1}{U 1(H 1-H 2)} \times\left[\int_{0}^{L} \frac{1}{E I(l)} \times d l-H 2 \times \int_{0}^{L} \frac{1}{E(l)} \times d l\right] \\
& Z 5=\frac{E I 2}{U 2(H 1-H 2)} \times\left[-\int_{0}^{L} \frac{l}{E I(l)} \times d l+\int_{0}^{L} \frac{1}{E I l(l)} \times d l\right] ;
\end{aligned}
$$

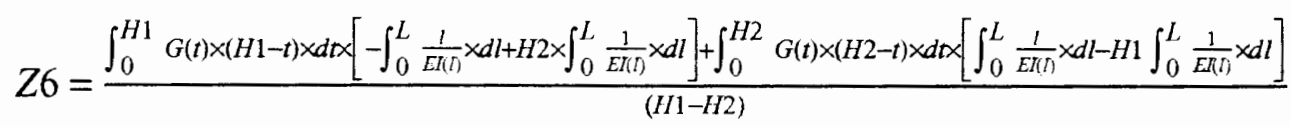

$$
\begin{aligned}
& +\int_{0}^{L} \frac{1}{E I(l)} \times\left[\int_{0}^{l} G(t) \times(l-t) \times d t\right] \times d l .
\end{aligned}
$$

The equations (2.15) and (2.16) describe the relationship between the bending deflections and the bending strains. Since Z1..Z6 don't contain any external payload 
variables or orientation of the link, they are constants for a particular link as the locations of the strain measurements are fixed.

\section{5 DISCUSSION ON CONSTANT Zs}

The constants $\mathrm{Z} 1$ through $\mathrm{Z6}$ obtained in last section contain the information on the shape and the material properties of the link that are necessary to describe the deflection behavior of the link. For the links having simple shape and uniform material characteristic, the Zs can be calculated from geometry and bending stiffness of the link. A constant cross-section and uniformly distributed link for instance, the constant Zs associated with the link become equations (2.17)...(2.22).

$$
\begin{aligned}
& Z 1=\frac{L^{2}}{U \times(H 1-H 2)} \times\left(\frac{L}{3}-\frac{H 2}{2}\right) \\
& Z 2=\frac{L^{2}}{U \times(H 1-H 2)} \times\left(\frac{H 1}{2}-\frac{L}{3}\right) \\
& Z 3=\frac{G \times\left(-\frac{H 1^{2} \times L^{3}}{6}+\frac{H 1^{2} \times H 2 \times L^{2}}{4}+\frac{H L^{2} \times L^{3}}{6}-\frac{H 2^{2} \times H 1 \times L^{2}}{4}\right)}{E I \times(H 1-H 2)}+\frac{G \times L^{4}}{8 \times E I} \\
& Z 4=\frac{L}{U \times(H 1-H 2)} \times\left(\frac{L}{2}-H 2\right) \\
& Z 5=\frac{L}{U \times(H 1-H 2)} \times\left(H 1-\frac{L}{2}\right) \\
& Z 6=\frac{G \times\left(-\frac{H 1^{2} \times L^{2}}{4}+\frac{H 1^{2} \times H 2 \times L}{2}+\frac{H 2^{2} \times L^{2}}{4}-\frac{H 2 \times H 1 \times L}{2}\right)}{E I \times(H 1-H 2)}+\frac{G \times L^{3}}{6 \times E I}
\end{aligned}
$$


For the links having complex geometry, it is difficult to get these constants mathematically. However as it will be shown in Chapter III, these constants can be obtained rather easily using an experimental identification method $[2,13]$. The identification method can also avoid errors caused by the inaccuracies of the geometry and the elastic properties of the link which are important for determining the deflection by other mathematical methods. Notice that the payload needs not be known to determine the deflections of the links. This gives the great flexibility to the manipulators in practical usage where the payload varies from task to task.

The equations (2.15) and (2.16) are based on the small deflection assumption. The deflections are linearly proportional to the bending strains measured in locations $\mathrm{H} 1$ and H2. Once the deflection becomes large, the equation describing the bending moment along the link is no longer valid. The strain energy calculated using the bending moment equation can not be a good approximation of the actual strain energy. The relationship between the deflection and the strain is no longer linear. 


\section{CHAPTER III}

\section{EXPERIMENTAL VERIFICATION OF DEFLECTION MODEL}

\section{III.1 INTRODUCTION}

The mathematical model relating the strains to deflection has been developed in

Chapter II. This chapter describes the experimental setup for verification of the strain-deflection model and presents the experimental results. Two experiments are conducted to verify the mathematical deflection model. First, an experiment is performed on a circular aluminum bar with known geometry and elastic properties. With the known geometry and elastic properties of the aluminum bar, the theoretical parameters of the model can be obtained using the equations developed in Chapter II. The parameters of model can also be obtained using experimental identification method. The theoretical and experimental parameters are compared. The aluminum bar is then replaced with a composite hollow cylinder beam with unknown cross-section and elastic properties for the second experiment. The parameters of the strain-deflection model of the composite cylinder are obtained using the experimental identification method and experimental model is used to predict the deflection. The predicted deflection using the model is compared with the actually measured deflection. 


\section{III.2 EXPERIMENTAL SETUP}

For the experiment to verify the strain-deflection model, three parts of experimental setup are required: a measurement system that can measure displacement in a vertical plane accurately, a rotary indexer that can firmly hold and rotate the link in accurate angles to simulate the link in different orientations under payload, and a strain measurement system that can measure the strain accurately. The schematic of the experimental setup is shown in Figure 5.

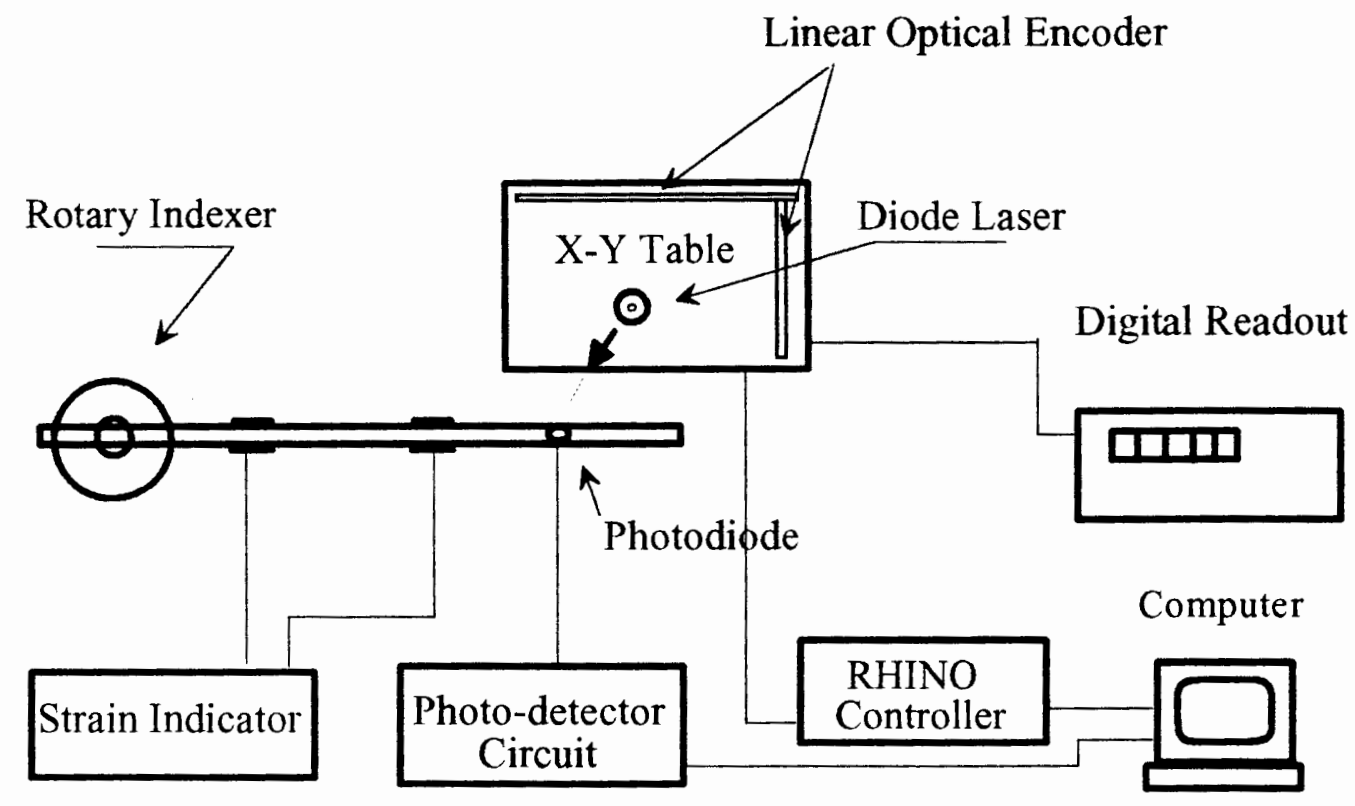

Figure 5. Experimental Setup for the Verification of Strain-deflection Model. 
An X-Y table linear measurement system with linear optical encoders is built and mounted on a $4 * 4 \mathrm{ft}$ square aluminum plate as shown in Figure 5 . The aluminum plate is mounted on a vertical wall. The $\mathrm{X}-\mathrm{Y}$ table is calibrated in honizontal-vertical direction. The $\mathrm{X}-\mathrm{Y}$ table is driven by two motors and the movements of the motors are controlled by a computer through a RHINO controller. A program is written to control the linear measurement automatically. A diode laser generator is fixed with the X-Y table. So the movement distance of the laser generator is recorded by the linear optical encoders. The laser is detected by a photo diode which is mounted on the point to be measured. The signal detected by the photo diode is processed by a circuit so that a $\mathrm{ON}$ signal is sent out when the laser points the center of the photo diode (Figure 6). The resolution of the laser-detector system is adjusted by adjusting the potentio meter shown in Figure 6 . This On signal is sent to the computer to control the linear measurement automatically.

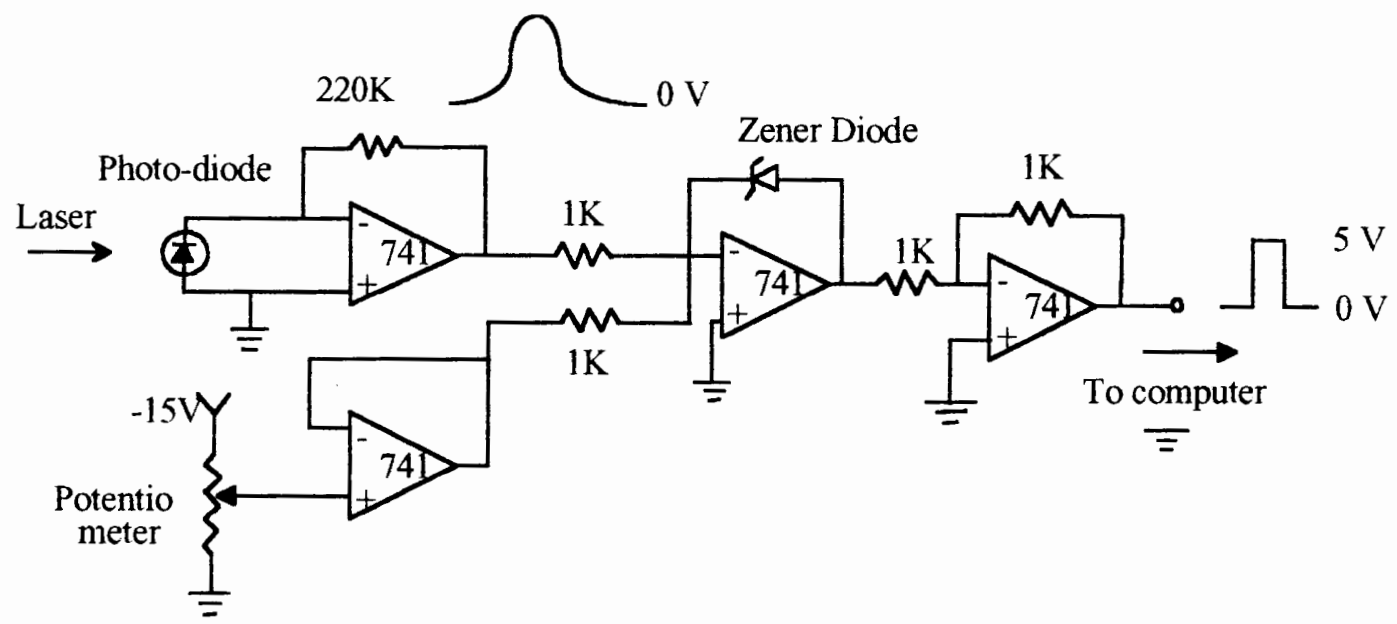

Figure 6. Photo-detector Circuit. 
A rotary indexer is used to hold the experimented links. The indexer can be rotated to simulate various angles of the link. The indexer can be moved around five stations on the aluminum plate to give different range of angles.

The strains are measured using P-3500 Digital Strain Indicator from Measurement Group Inc. P-3500 is designed for static strain measurement. It contains wheatstone bridge completion circuit and amplification circuit and can hold up to 10 channels with the SB-10 Switch Balance Unit. The operation of the strain indicator is referred to $[14,15]$.

\section{III.3 STRAIN AND DEFLECTION MEASUREMENTS}

It is shown in Chapter II that the bending strains at two different locations of the link can be measured to monitor the bending deflection of a flexible link. To measure the bending strain, half bridge configuration of wheatstone is employed. The two-active-arm bridge isolates the bending strain from axial strain. The center lines of the strain gages are placed in the symmetric plane of the link. The wheatstone bridge is completed inside P-3500 Digital Strain Indicator. The P-3500 automatically converts the voltage output of the wheatstone bridge to the strain and shows the strain on the digital readout. The strain is recorded by hand. Figure 7 . shows the wheatstone bridge completion and strain gage installation.

The linear transverse deflection is directly measured by the X-Y table. To measure the angular deflection, a additional point near the free end of the link is measured. The 
line connecting the additional point to the end point is used to approximate angular deflection.

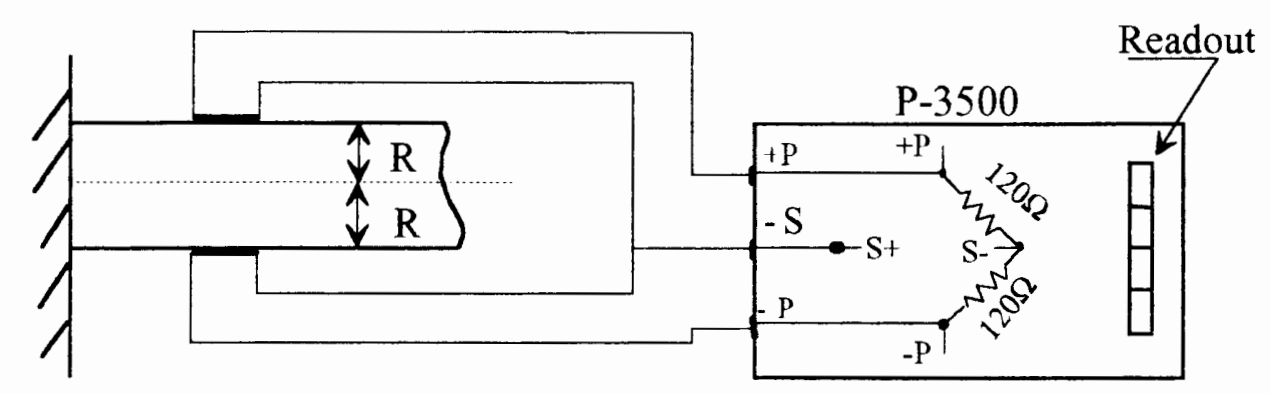

Figure 7. Wheatstone Bridge Completion.

\section{III.4 AN EXPERIMENT ON AN ALUMINUM BAR}

The verification experiment is first performed on a circular aluminum bar with two pairs of strain gages installed. The geometry and the bending stiffness of the aluminum bar are known. The physical parameters of the aluminum bar are shown in Table I. The constant Zs associated with the aluminum bar are theoretically calculated by (2.17) to (2.22) using the parameters in Table I.

To obtain the constant $\mathrm{Zs}$ for the aluminum bar experimentally, measurements are performed three times with different payload $\mathrm{P}$ and different loading points A (Figure 8). The transverse deflection, the angular deflection and the strains are measured. The data obtained is shown in Table II. 


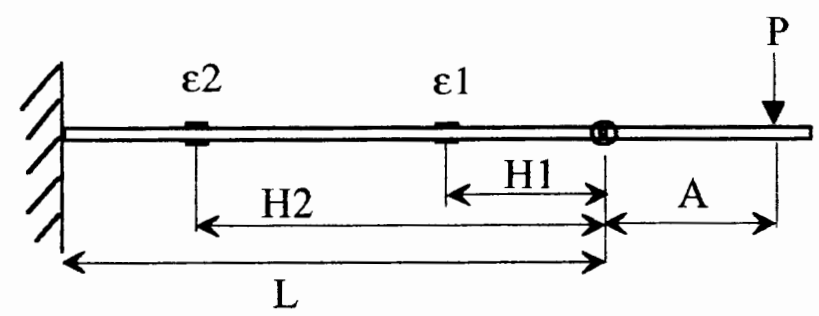

Figure 8. Loading Configuration.

TABLE I

PHYSICAL PARAMETERS FOR THE ALUMINUM BAR

\begin{tabular}{|l|l|l|l|}
\hline PARAMETER & SYMBOL & VALUE & UNITS \\
\hline \hline Length & L & 20 & inches \\
\hline Location of Strain1 & H1 & 5 & inches \\
\hline Location of Strain2 & H2 & 15 & inches \\
\hline Modules of Elasticity & E & $10 \times 10^{6}$ & ${\mathrm{lb} / \text { in }^{2}}^{2}$ \\
\hline Radius & $\mathrm{R}$ & 0.25 & inches \\
\hline
\end{tabular}

TABLE II

IDENTIFICATION DATA FOR THE ALUMINUM BAR

\begin{tabular}{|c|c|c|c|c|c|c|}
\hline Load \# & $\mathrm{P}(\mathrm{lb})$ & $\mathrm{A}($ inch) & $\varepsilon 1$ (micro-strain) & $\varepsilon 2$ (micro-strain) & $\Delta \mathrm{Lt}(\mathrm{inch})$ & $\delta \theta(\mathrm{rad})$ \\
\hline 1 & 3.5 & 0 & 178 & 504 & 0.39 & 0.027 \\
\hline 2 & 6.7 & 15 & 1,124 & 1,708 & 1.37 & 0.111 \\
\hline 3 & 9 & 0 & 423 & 1,210 & 0.92 & 0.063 \\
\hline
\end{tabular}


The three groups of experimental strains $(\varepsilon)$ and deflections $(\Delta \mathrm{Lt}, \delta \theta)$ are substituted to equations (2.15) and (2.16) to form six linear independent equations. The six constant $\mathrm{Zs}$ are solved from these six equations.

The experimental and theoretical Zs are shown and compared in Table III.

TABLE III

EXPERIMENTAL AND THEORETICAL ZS FOR THE ALUMINUM BAR

\begin{tabular}{|l|c|c|c|c|c|c|}
\hline & $\mathrm{Z} 1$ & $\mathrm{Z} 2$ & $\mathrm{Z3}$ & $\mathrm{Z} 4$ & $\mathrm{Z} 5$ & $\mathrm{Z} 6$ \\
\hline Experimental & 144.17 & 700.68 & 0.01 & 42.13 & 37.08 & 0 \\
\hline Theoretical & 133.33 & 666.67 & 0 & 40 & 40 & 0 \\
\hline
\end{tabular}

The experimental and theoretical Zs shown in Table III agree with each other with some differences. The factors causing these differences are the inaccuracies of the physical parameters, the deflection measurements and the strain measurements.

\section{III.5 AN EXPERIMENT ON}

\section{A COMPOSITE HOLLOW CYLINDER}

For a link with unknown geometry and elastic properties, the constant Zs can be obtained by experimental identification method. An experiment is conducted on a composite hollow cylinder with two pairs of strain gages installed. The cross-section and 
elastic properties of the composite cylinder are unknown. The length of the composite beam and the locations where the strain gages are installed are shown in Table IV.

TABLE IV

PHYSICAL PARAMETERS FOR THE COMPOSITE BEAM

\begin{tabular}{|l|l|l|l|}
\hline PARAMETER & SYMBOL & VALUE & UNIT \\
\hline Length & L & 27.5 & inches \\
\hline Location of Strain1 & H1 & 15 & inches \\
\hline Location of Strain2 & H2 & 5 & inches \\
\hline
\end{tabular}

Three groups of data are obtained experimentally with different loading conditions The data for identifying the $\mathrm{Zs}$ is obtained as shown in Table $\mathrm{V}$. It should be noted that the first group of data is set to zero. This is because the deflections of composite beam are very small under its own weight and they are neglected.

\section{TABLE V}

\section{IDENTIFICATION DATA FOR THE COMPOSITE BEAM}

\begin{tabular}{|c|c|c|c|c|c|c|}
\hline Load \# & $\mathrm{P}(\mathrm{lb})$ & $\mathrm{A}$ (inches) & $\varepsilon 1$ (micro-strain) & $\varepsilon 2$ (micro-strain) & $\Delta \mathrm{Lt}$ (inches) & $\delta \theta(\mathrm{Rad})$ \\
\hline 1 & 0 & 0 & 0 & 0 & 0 & 0 \\
\hline 2 & 1.6 & 0.2 & 699 & 2,576 & 2.6 & 0.136 \\
\hline 3 & 0.83 & 21 & 1,763 & 2,315 & 2.74 & 0.17 \\
\hline
\end{tabular}


As it is done to the aluminum bar, the identification data is substituted to equations (2.15) and (2.16) to obtained the constant $Z s$ associated with the composite beam. The resulting Zs are shown in Table VI.

\section{TABLE VI}

\section{CONSTANT ZS FOR THE COMPOSITE BEAM}

\begin{tabular}{|c|c|c|c|c|c|}
\hline $\mathrm{Z} 1$ & $\mathrm{Z} 2$ & $\mathrm{Z3}$ & $\mathrm{Z} 4$ & $\mathrm{Z} 5$ & $\mathrm{Z} 6$ \\
\hline 355.89 & 912.55 & 0 & 42.25 & 41.32 & 0 \\
\hline
\end{tabular}

After the constant Zs associated with the composite beam are obtained, the deflections can be monitored by measuring the bending strains. Even though the Zs are obtained with the link in horizontal direction, it is shown in Chapter II that the constants Zs are independent of the orientation of the link. This strain-deflection model should be able to model the deflection of the link in different orientations. To proof that the deflection can be accurately monitored for various loading conditions, the beam is loaded with different loading conditions in different orientations. The deflections are actually measured using the $\mathrm{X}-\mathrm{Y}$ table linear measurement system and predicted by measuring the strains. Table VII shows the parameters for 14 groups of measurements performed.

The predicted deflections are compared with the deflections actually measured. The experimental results of loading group\#1 are shown in Figure 9. The results of this experiment show that the bending deflections in a plane can be monitored rather 
accurately using the strain-deflection model developed in Chapter II by measuring bending strains at two different locations.

It is noted in Figure 9 that there are differences between the predicted deflections and actually measured deflections. These differences are due to the inaccuracies of the deflection measurements and the strain measurements.

TABLE VII

LOADING PARAMETERS FOR THE COMPOSITE BEAM

\begin{tabular}{|c|c|c|}
\hline Group \# & Orientation $\theta$ (deg) & $\begin{array}{c}\text { Loading Location } \\
\text { A(inches) }\end{array}$ \\
\hline 1 & 0 & 0.2 \\
\hline 2 & 0 & 10 \\
\hline 3 & 0 & 21 \\
\hline 4 & 9 & 0.2 \\
\hline 5 & 9 & 10 \\
\hline 6 & 9 & 21 \\
\hline 7 & 50 & 1 \\
\hline 8 & 50 & 10 \\
\hline 9 & 50 & 21 \\
\hline 10 & 70 & 10 \\
\hline 11 & 70 & 21 \\
\hline 12 & -12 & 0.2 \\
\hline 13 & -12 & 10 \\
\hline 14 & -12 & 21 \\
\hline
\end{tabular}



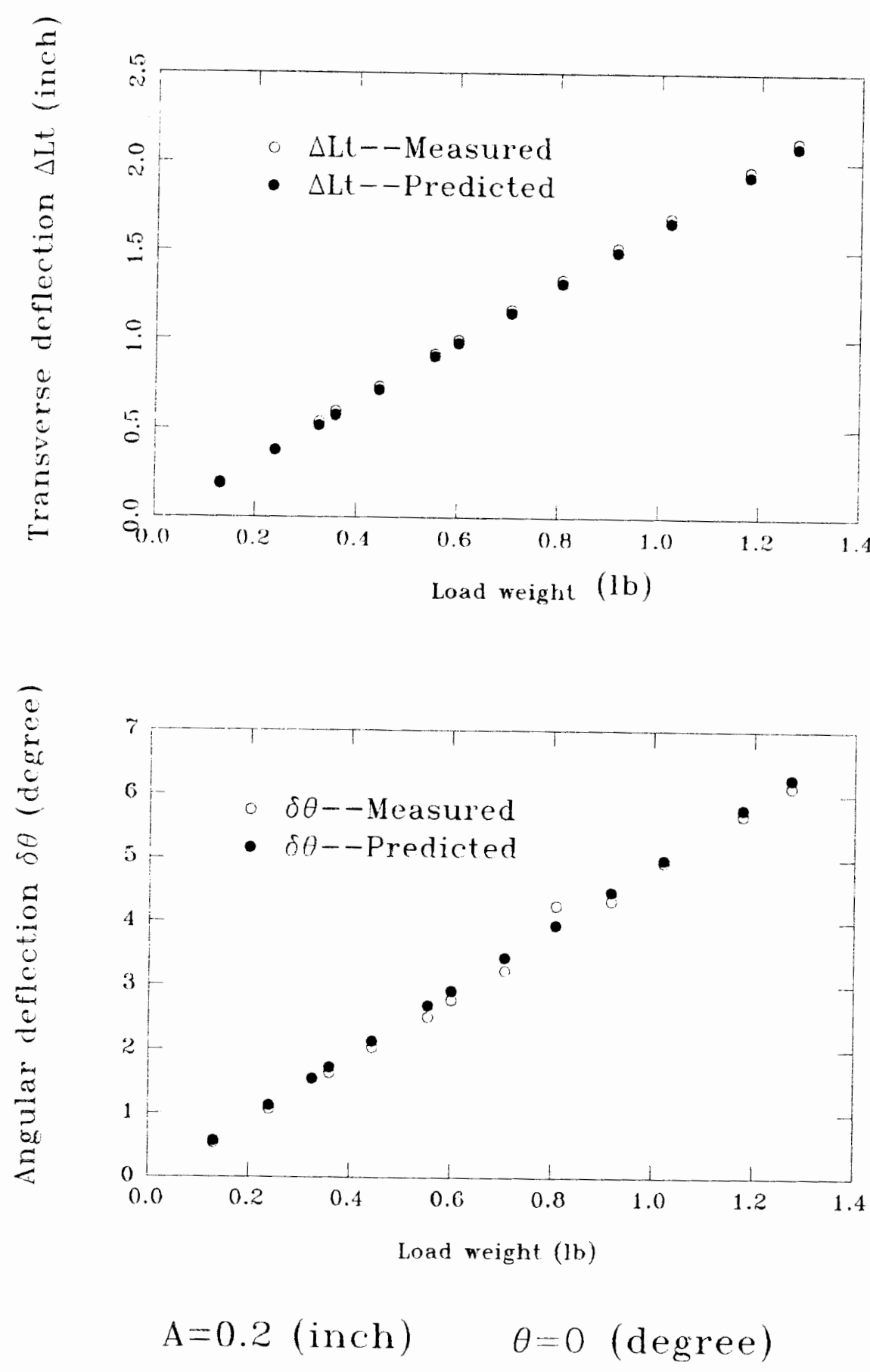

Figure 9. Experimental Result for Composite Beam, Loading Group \#1. 


\section{CHAPTER IV}

\section{CONTROL ALGORITHM}

\section{IV.1 INTRODUCTION}

The kinematics of manipulator with rigid links have been completely described using the symbolic notation of the Hartenberg-Denavit Matrix [11]. The flexibility of the manipulator links can be described by inserting deviation matrices. The elements of these matrices are functions of the structural deflections. The forward and inverse kinematics including deviation matrices can be solved symbolically yielding closed-form inverse solution. The deflections are included in the kinematic models as variables. Using the forward kinematics, the actual position of the end-effector can be calculated with joint variables feedback from the servo joints and deflections monitored from the strain gages. With the final deflections are approximated by the current deflections monitored by strain gages, the modified joint angles are computed. This kinematic model is used in developing the control algorithm of flexible manipulator. 


\section{IV.2 KINEMATIC ANALYSIS}

To describe the kinematics of a manipulator, homogeneous transformation is used. Coordinates are assigned to individual joints to represent the relative position and orientation as shown in Figure 10. The Hartenberg-Denavit matrix $T_{i}^{i+1}$ relates the ith and $(i+1)$ coordinates and it is a function of kinematic parameters and joint variables. The Hartenberg-Denavit matrix can be expressed as equation (4.1):

$$
T_{i}^{i+1}=\left[\begin{array}{cccc}
r_{11} & r_{12} & r_{13} & P_{x} \\
r_{21} & r_{22} & r_{23} & P_{y} \\
r_{31} & r_{32} & r_{33} & P_{z} \\
0 & 0 & 0 & 1
\end{array}\right]
$$

where, the $3 \times 3$ matrix $R$ describes the orientation of frame $(i+1)$ with respect to frame $i$, and the vector $P$ describes the position of frame $(i+1)$ with respect to frame $i$.

For rigid manipulator system, the kinematics is completely described by homogeneous transformation matrices. A kinematic model includes forward kinematics and inverse kinematics. The forward kinematics is obtained by multiplying the transformation matrices as in equation (4.2). The $T_{0}^{\text {End }}$ describes the position and orientation of the end-effector for a given set of joint variables. The inverse kinematics is obtained by solving a set of joint variables from equation (4.2) for desired position and orientation of the end-effector.

$$
T_{0}^{E n d}=T_{0}^{1} T_{1}^{2} \ldots T_{i}^{i+1} \ldots T_{n-1}^{n}
$$




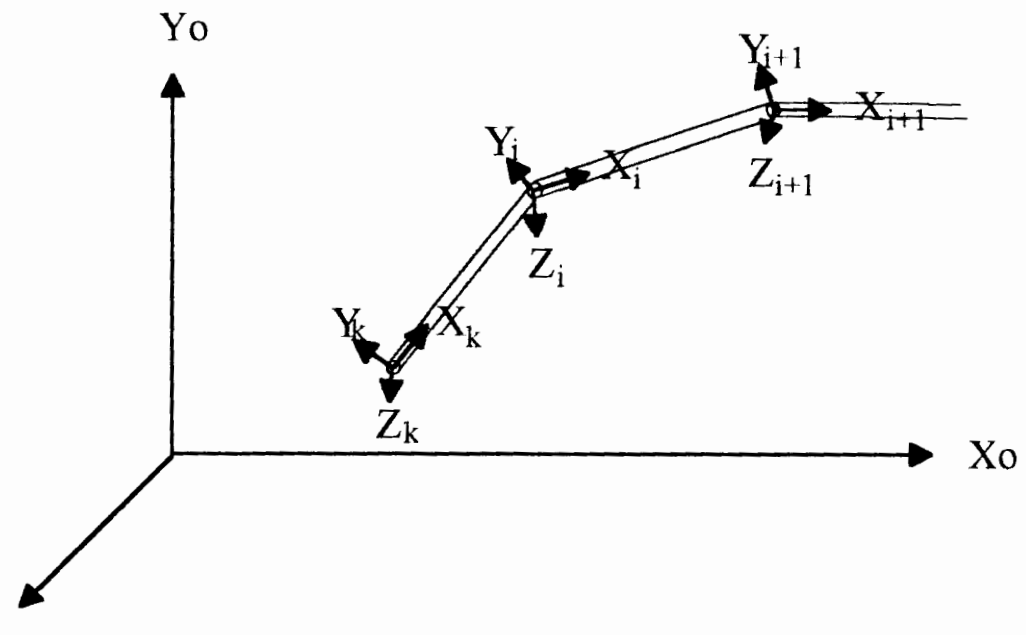

Figure 10. Coordinate System for Rigid Manipulator.

Because of the deflections of the links, the actual attained configurations are different from the configurations of the rigid-link system. The actual position and orientation of the end-effector will not match the desired position and orientation as the joints reach the command joint angles from the rigid inverse kinematics. The deflections of links must be included in the kinematic model to describe the manipulator accurately. To describe the deflections of the links, extra coordinates are introduced as shown in Figure 11. These extra coordinates are assigned to present the actual positions and orientation of joints.

The homogeneous transformation matrices are used to relate the nominal and actual joints. These matrices are called deviation matrices $T_{i}^{\prime}[10]$. The deviation matrices are functions of deflections of the link. 


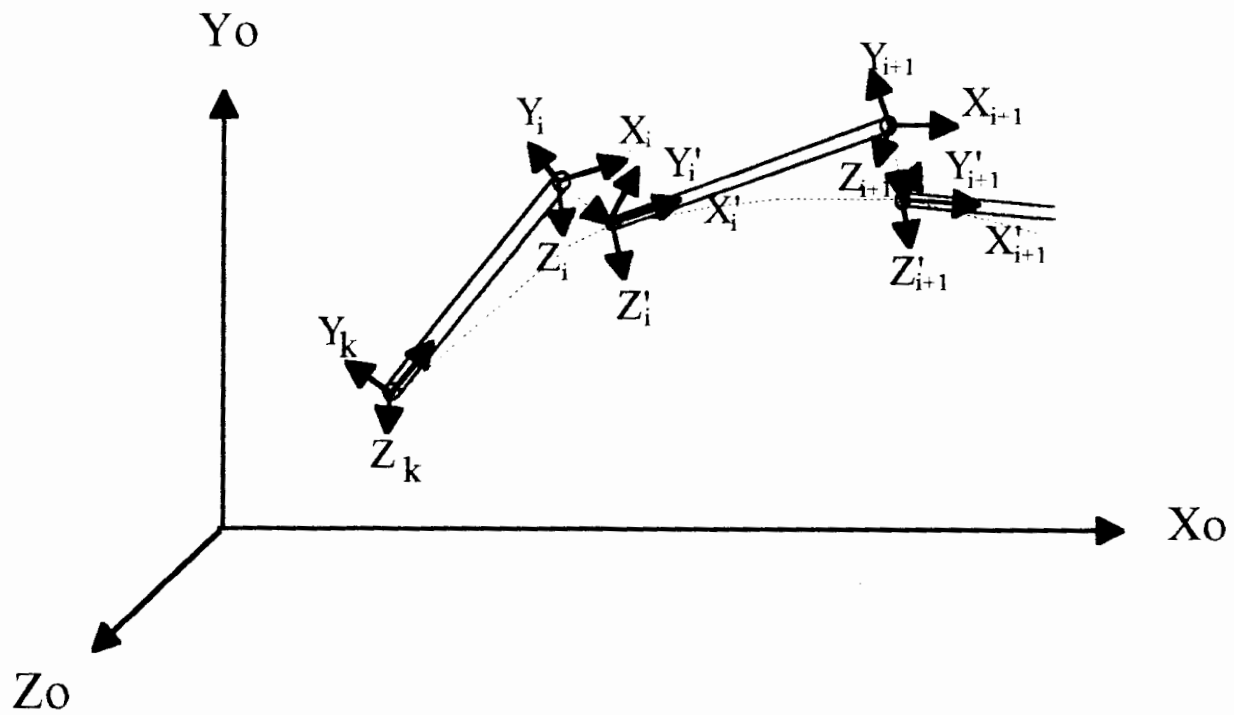

Figure 11. Coordinate System for Flexible Manipulator.

The Hartenberg-Denavit matrix then is modified to include the deflections as in equation (4.3).

$$
T_{i}^{i+1}=T_{i}^{i+1} T_{i+1}^{\prime}
$$

By including the deviation matrices in the kinematic model, the model describes the kinematics of the flexible manipulator. Because the deflections vary with the payload and the configuration of the manipulator, the deflections appear in the kinematics model as variables. If the deflections are known, the actual end-effector position and orientation of the flexible manipulator can be determined for a set of joint variables using the forward kinematics and a set of joint variables can be determined for desired end-effector position and orientation using inverse kinematics 
The forward kinematics of a manipulator can be always obtained in closed-form. However the inverse kinematics of a manipulator does not always provide a closed-form solution. A closed-form inverse kinematic solution is very useful for on-line, real-time manipulator control because of the computational efficiency. It has shown that a closed-form inverse solution can be obtained for a manipulator which has three consecutive joints whose joint axes intersect at a point [16]. For the manipulators without closed-form solutions, the inverse kinematics can be solved using numerical techniques. But the amount of computational time required by the numerical techniques is generally large. Hence the numerical techniques are not suitable for the real-time control algorithm except a very efficient numerical technique is developed.

As an example, the inverse kinematics of a planar flexible manipulator with three degrees-of-freedom will be solved in closed-form including the deflections as variables in next section.

\section{IV.3 AN EXAMPLE OF KINEMATIC MODEL}

\section{FOR A PLANAR MANIPULATOR WITH THREE FLEXIBLE LINKS}

To use the control algorithm presented later, kinematic model which includes the deflections as variables is needed. This section presents an example of kinematic model which includes the deflections for a planar manipulator with three revolute joints. The inverse kinematics is solved in closed-form for the computational efficiency. Figure 12 shows the configuration and the coordinates assignment of the manipulator. 


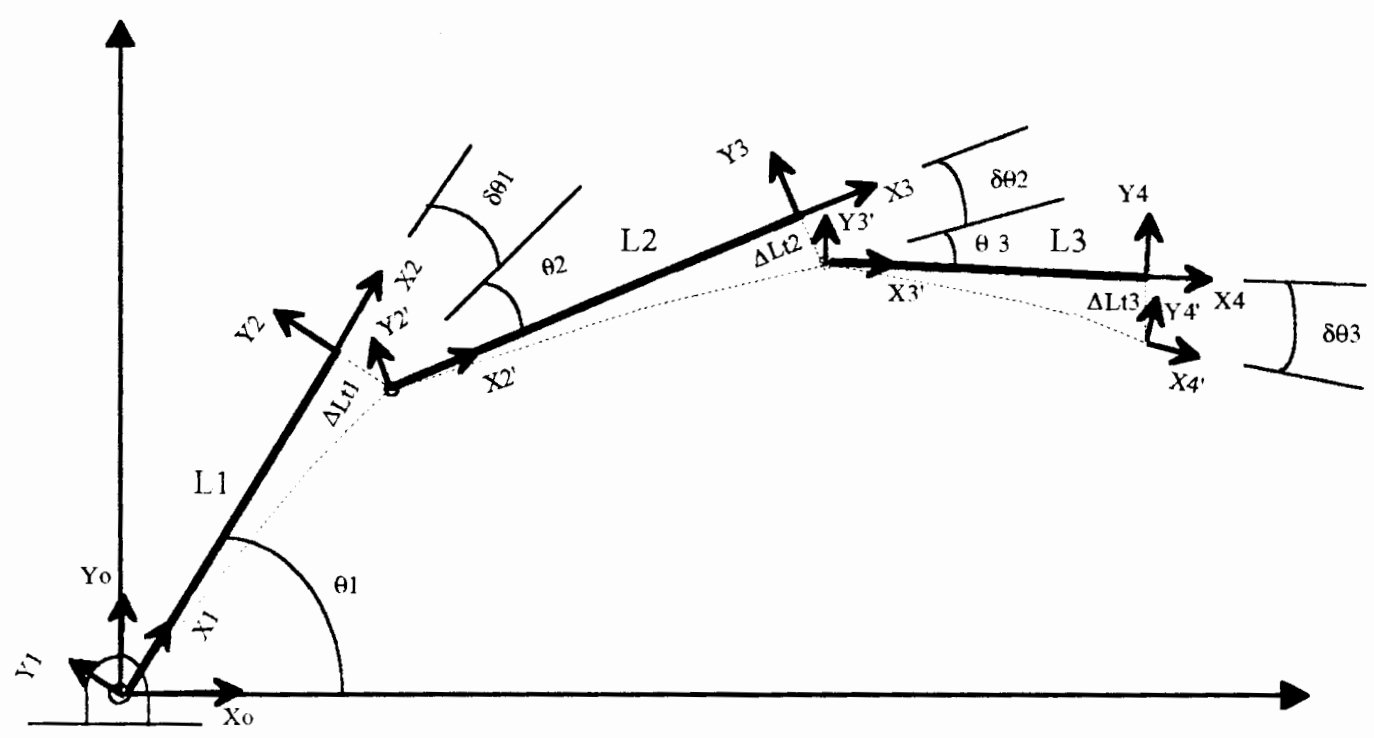

Figure 12. Kinematics for A Manipulator with Three Flexible Links

The parameters and variables for the manipulator are shown in Table VIII.

TABLE VIII

PARAMETERS AND VARIABLES FOR THE FLEXIBLE MANIPULATOR WITH THREE FLEXIBLE LINKS

\begin{tabular}{|l|l|l|l|}
\hline PARAMETER & JOINT VARIABLE & $\begin{array}{c}\text { LINEAR } \\
\text { DEFLECTION } \\
\text { VARIABLE }\end{array}$ & $\begin{array}{c}\text { ANGULAR } \\
\text { DEFLECTION } \\
\text { VARIABLE }\end{array}$ \\
\hline $\mathrm{L} 1$ & $\Delta 1$ & $\Delta L t 1$ & $\delta \theta 1$ \\
\hline $\mathrm{L} 2$ & $\theta 2$ & $\Delta L t 2$ & $\delta \theta 2$ \\
\hline $\mathrm{L} 3$ & $\theta 3$ & $\Delta L t 3$ & $\delta \theta 3$ \\
\hline
\end{tabular}


Substituting the parameters and variables in Table VIII into the Hartenberg-Denavit matrices, the transformation matrices relating the coordinates are obtained as in equations (4.4) through (4.10).

$$
\begin{aligned}
& T_{0}^{1}=\left[\begin{array}{cccc}
\cos \theta 1 & -\sin \theta 1 & 0 & 0 \\
\sin \theta 1 & \cos \theta 1 & 0 & 0 \\
0 & 0 & 1 & 0 \\
0 & 0 & 0 & 1
\end{array}\right] \\
& T_{1}^{2}=\left[\begin{array}{cccc}
\cos \theta 2 & -\sin \theta 2 & 0 & L 1 \\
\sin \theta 2 & \cos \theta 2 & 0 & 0 \\
0 & 0 & 1 & 0 \\
0 & 0 & 0 & 1
\end{array}\right] \\
& T_{2}^{\prime}=\left[\begin{array}{cccc}
\cos \delta \theta 1 & -\sin \delta \theta 1 & 0 & -\Delta L t 1 \times \sin \theta 2 \\
\sin \delta \theta 1 & \cos \theta 1 & 0 & -\Delta L t 1 \times \cos \theta 2 \\
0 & 0 & 1 & 0 \\
0 & 0 & 0 & 1
\end{array}\right] \\
& T_{2}^{3}=\left[\begin{array}{cccc}
\cos \theta 3 & -\sin \theta 3 & 0 & L 2 \\
\sin \theta 3 & \cos \theta 3 & 0 & 0 \\
0 & 0 & 1 & 0 \\
0 & 0 & 0 & 1
\end{array}\right] \\
& T_{3}^{\prime}=\left[\begin{array}{cccc}
\cos \delta \theta 2 & -\sin \delta \theta 2 & 0 & -\Delta L t 2 \times \sin \theta 3 \\
\sin \delta \theta 2 & \cos \delta \theta 2 & 0 & -\Delta L t 2 \times \cos \theta 3 \\
0 & 0 & 1 & 0 \\
0 & 0 & 0 & 1
\end{array}\right]
\end{aligned}
$$




$$
\begin{aligned}
& T_{3}^{4}=\left[\begin{array}{cccc}
1 & 0 & 0 & L 3 \\
0 & 1 & 0 & 0 \\
0 & 0 & 1 & 0 \\
0 & 0 & 0 & 1
\end{array}\right] \\
& T_{4}^{\prime}=\left[\begin{array}{cccc}
\cos \delta \theta 3 & -\sin \delta \theta 3 & 0 & 0 \\
\sin \delta \theta 3 & \cos \delta \theta 3 & 0 & -\Delta L t 3 \\
0 & 0 & 1 & 0 \\
0 & 0 & 0 & 1
\end{array}\right]
\end{aligned}
$$

The matrix describing the end-effector $T_{0}^{E n d}$ is obtained by multiplying the transformation matrices as in equation (4.11).

$$
T_{0}^{E n d}=T_{0}^{1} T_{1}^{2} T_{2}^{\prime} T_{2}^{3} T_{3}^{\prime} T_{3}^{4} T_{4}^{\prime}
$$

The forward and inverse kinematics are solved from equation (4.11). Equations (4.12), (4.13) and (4.14) are the forward kinematics. Equations (4.15), (4.16) and (4.17) are the inverse kinematics.

$$
\begin{aligned}
X_{\text {End }}= & L 1 \times \cos \theta 1+L 2 \times \cos (\theta 1+\theta 2+\delta \theta 1) \\
& +L 3 \times \cos (\theta 1+\theta 2+\theta 3+\delta \theta 1+\delta \theta 2) \\
& +\Delta L t 1 \times \sin \theta 1+\Delta L t 2 \times \sin (\theta 1+\theta 2+\delta \theta 1) \\
& +\Delta L t 3 \times \sin (\theta 1+\theta 2+\theta 3+\delta \theta 1+\delta \theta 2) \\
Y_{\text {End }}= & L 1 \times \sin \theta 1+L 2 \times \sin (\theta 1+\theta 2+\delta \theta 1) \\
& +L 3 \times \sin (\theta 1+\theta 2+\theta 3+\delta \theta 1+\delta \theta 2) \\
& -\Delta L t 1 \times \cos \theta 1-\Delta L t 2 \times \cos (\theta 1+\theta 2+\delta \theta 1) \\
& -\Delta L t 3 \times \cos (\theta 1+\theta 2+\theta 3+\delta \theta 1+\delta \theta 2)
\end{aligned}
$$




$$
\begin{aligned}
& \theta_{E n d}=\theta 1+\theta 2+\theta 3+\delta \theta 1+\delta \theta 2+\theta 3 \\
& \theta 1=\operatorname{Arctan} 2(K 1,-K 4)-\operatorname{Arctan} 2(K 2, K 3)
\end{aligned}
$$

where $K 1=X-L 3 \times \cos \left(\theta_{\text {End }}-\delta \theta 3\right)-\Delta L t 3 \times \sin \left(\theta_{\text {End }}-\delta \theta 3\right)$;

$$
\begin{aligned}
& K 2=L 1+L 2 \times \cos (\theta 2+\delta \theta 1)+\Delta L t 2 \times \sin (\theta 2+\delta \theta 1) \\
& K 3=\Delta L t 1-L 2 \times \sin (\theta 2+\delta \theta 1)+\Delta L t 2 \times \cos (\theta 2+\delta \theta 1) ; \\
& K 4=Y-L 3 \times \sin \left(\theta_{\text {End }}-\delta \theta 3\right)+\Delta L t 3 \times \cos \left(\theta_{\text {End }}-\delta \theta 3\right) . \\
& \theta 2=2 \times \operatorname{Arctan} 2 \times\left[\left(K 6 \pm \sqrt{K 5^{2}+K 6^{2}-K 7^{2}}\right),(K 5+K 7)\right]-\delta \theta 1
\end{aligned}
$$

where $K 5=2 \times L 1 \times L 2+2 \times \Delta L t 1 \times \Delta L t 2$;

$$
\begin{aligned}
& K 6=2 \times L 1 \times \Delta L t 2-2 \times L 2 \times \Delta L t 1 \\
& K 7=X^{2}+Y^{2}+L 3^{2}+\Delta L t 3^{2}-L 1^{2}-L 2^{2}-\Delta L t 1^{2}-\Delta L t 2^{2} . \\
& \theta 3=\theta_{\text {End }}-(\theta 1+\theta 2+\delta \theta 1+\delta \theta 2+\delta \theta 3)
\end{aligned}
$$

\section{IV.4 CONTROL ALGORITHM}

To compensate the end-effector error due to the deflections of the manipulator links, a control algorithm is developed in this section. As described earlier, the deflections of individual links are monitored in real-time by measuring the strains in this approach. The deflections can be detected without directly measuring the payload. Unlike the deflections determined using other mathematical modeling methods, the final deflections are unknown before the manipulator reaches to the final configuration. Because the 
deflection information is feedback in real-time, the real-time deflection compensation control algorithm is employed and the inverse kinematics is solved in real-time. As discussed in the last section, the forward and inverse kinematics can be solved including the deflections as variable. The closed-form inverse kinematic solutions is assumed to be available.

The flow chart of the algorithm for deflection compensation control of flexible manipulators is shown in Figure 13. In this control loop, the deflections of individual links at current configuration are monitored from the strain gages. The actual position and orientation of the end-effector are computed with the deflection feedback and servo joint feedback using the forward kinematics which includes the deflections as variables. The actual position and orientation then are compared with the desired position and orientation. If the convergent criteria is satisfied, the current joint angles are desired joint angles for the desired position and orientation of the end-effector. If the convergent criteria is not satisfied, the current deflections are used to approximate the deflections at target configuration and the inverse kinematic calculation is performed to obtain a set of modified joint command angles. This set of joint command are output to the joint actuators. The deflections feedback and the servo joint variables feedback are again used to find the actual position and orientation of the end-effector. This control loop is closed until the end-effector reaches the desired position and orientation with a certain error boundary. This control algorithm will be simulated in a computer in next chapter. 


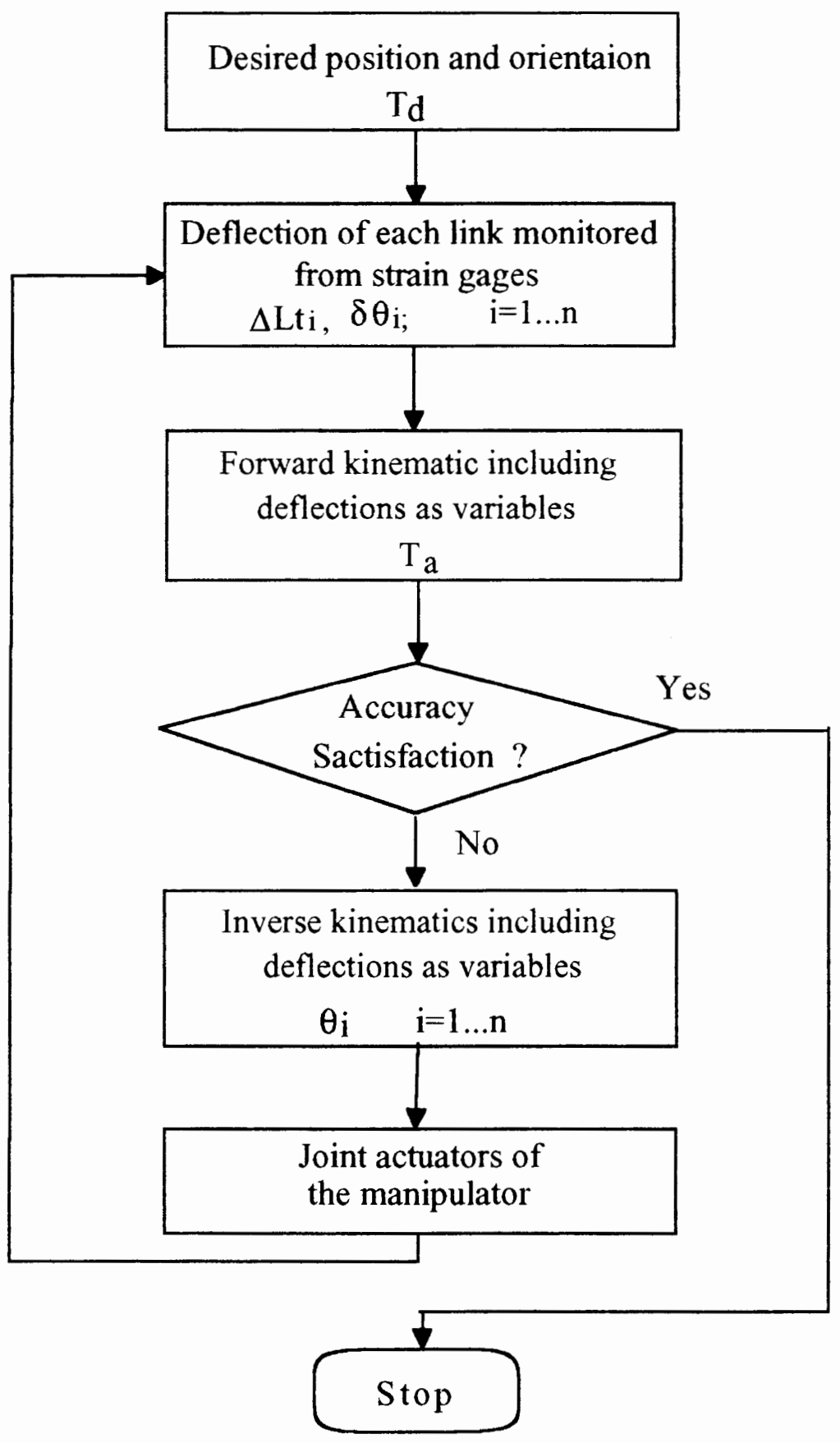

Figure 13. Flow Chart of Deflection Compensation Control. 


\section{CHAPTER V}

\section{COMPUTER SIMULATION}

\section{V.1 INTRODUCTION}

The deflection compensation control algorithm has been developed in Chapter IV. It is desirable to undertake a computer simulation of the control algorithm before it is verified experimentally. A simulation program is developed. The simulation program can simulate quasi-static control of rigid and flexible planar manipulators. This chapter presents the description of the simulation program and the simulation results. The results of using deflection compensation control algorithm are compared with the results using rigid-body control algorithm.

\section{V.2 DESCRIPTION OF THE SIMULATION PROGRAM}

The simulation program is written based on the 3 degrees-of-freedom planar manipulator presented in Chapter IV. The parameters of the manipulator are interactively provided by a user, then the configuration of the manipulator and the final simulation result are shown on the screen graphically as shown in Figure 14. The detailed simulation 


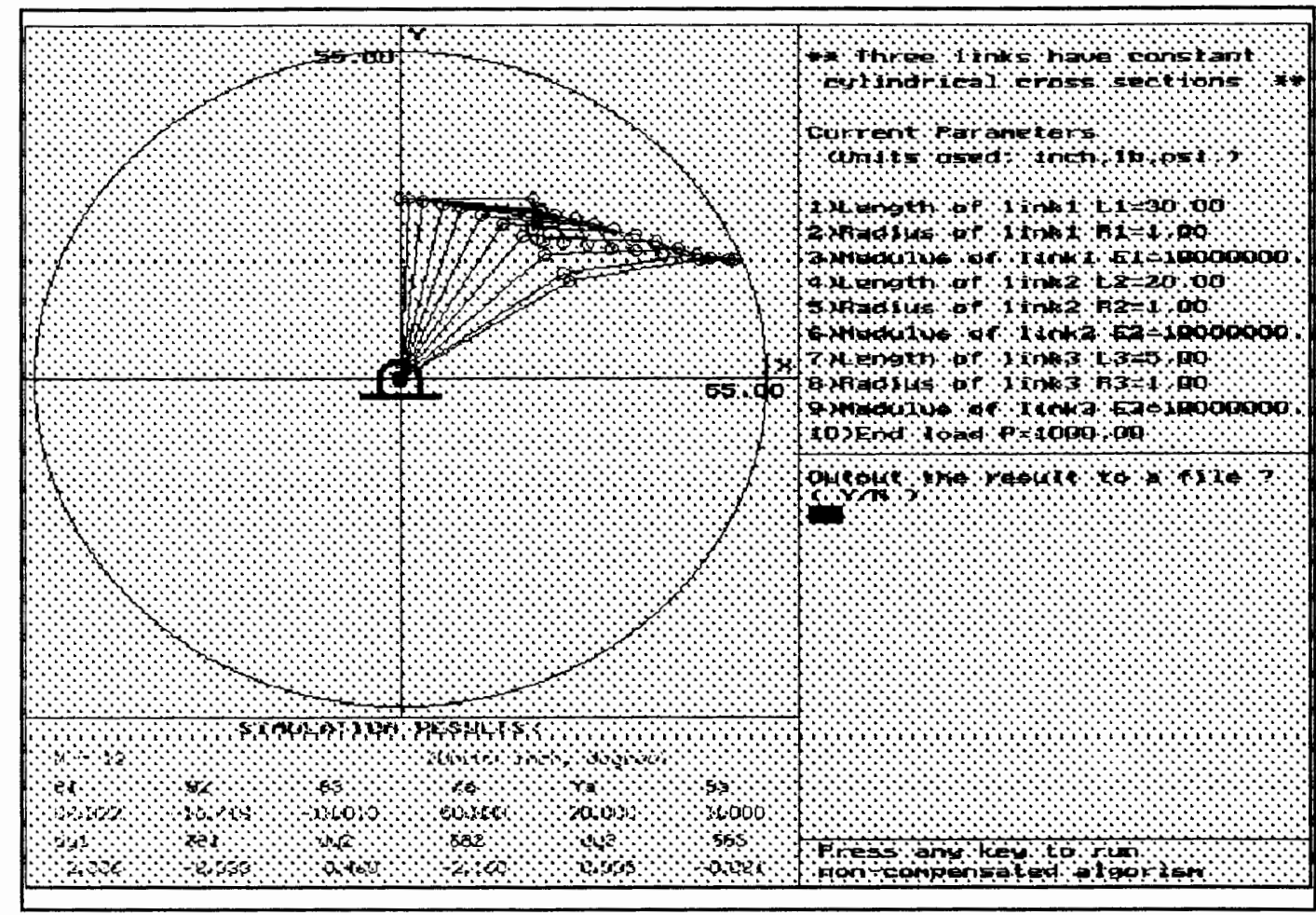

Figure 14. Screen of simulation Program. 
results of different variables used in the simulation can be chosen to output to data files for later analysis. Because the deflections of individual links needed to perform the forward and inverse kinematic calculations can not be monitored from strain gages in the simulation program, the deflections of individual links are calculated using energy method instead. For the simplicity of deflection calculation in the program, the flexible links of the manipulator are assumed to be constant cross-section and uniformly distributed. The quasi-stajc motion is assumed to exclude the effect of dynamic which is not concerned in this stage of study.

\section{V.3 SIMULATIONS}

To reach a desired point with desired orientation for a planar manipulator, at least three degrees-of-freedom are needed. Hence the deflection compensation control is simulated on a planar manipulator with three flexible links connected by three revolute joints. The joints are assumed to be rigid. One set of representative parameters of the planar manipulator are as shown in Table IX. The bending deflections are due to the payload and the own weight of the manipulator. The kinematics of three-link manipulator developed in Section IV.3 and the control algorithm developed in Section IV.4 are used for the simulation.

The simulations are performed on the flexible manipulator in two modes, point-to-point mode and path mode. In point-to-point mode the manipulator is moved to the target using rigid-body control algorithm, then the compensated control algorithm is 
used to correct the position error of the end-effector from there. In path mode the compensated control algorithm is used throughout the path movement.

TABLE IX

PARAMETERS OF THE MANIPULATOR FOR SIMULATION

\begin{tabular}{|l|l|l|l|}
\hline PARAMETER & SYMBOL & VALUE & UNIT \\
\hline Length of Link 1 & L1 & 30.00 & inches \\
\hline Radius of Link 1 & R1 & 0.50 & inches \\
\hline Modules of Elasticity of Link 2 & E1 & $10 \mathrm{e} 6$ & $l \mathrm{lb} / \mathrm{in}^{2}$ \\
\hline Length of Link 2 & $\mathrm{R} 2$ & 20.00 & inches \\
\hline Radius of Link 2 & L2 & 0.50 & inches \\
\hline Modules of Elasticity of Link 2 & E2 & $10 \mathrm{e} 6$ & $\mathrm{lb} / \mathrm{in}^{2}$ \\
\hline Length of Link 3 & L3 & 5.00 & inches \\
\hline Radius of Link 3 & $\mathrm{R} 3$ & 0.50 & inches \\
\hline Modules of Elasticity of Link 3 & E3 & $10 \mathrm{e} 6$ & ${\mathrm{lb} / \mathrm{in}^{2}}^{2}$ \\
\hline
\end{tabular}

Four target positions and orientations are input in to the simulation program in point-to-pint mode as shown in Figure 15. The position and orientation of the end-effector is present in vector form $(X, Y, \theta)$, where $X$ is the position in horizontal direction, $\mathrm{Y}$ is the position in vertical direction and $\theta$ is the orientation with reference to $\mathrm{x}$ axis. The final achieved positions and orientations for $10 \mathrm{lb}$ payload are shown in Table X. The final positions and orientations for $20 \mathrm{lb}$ payload are shown in Table XI. From the simulation results in Table $\mathrm{X}$ and Table XI, it can been seen that the compensation algorithm converges and the errors due to the deflections of the flexible 


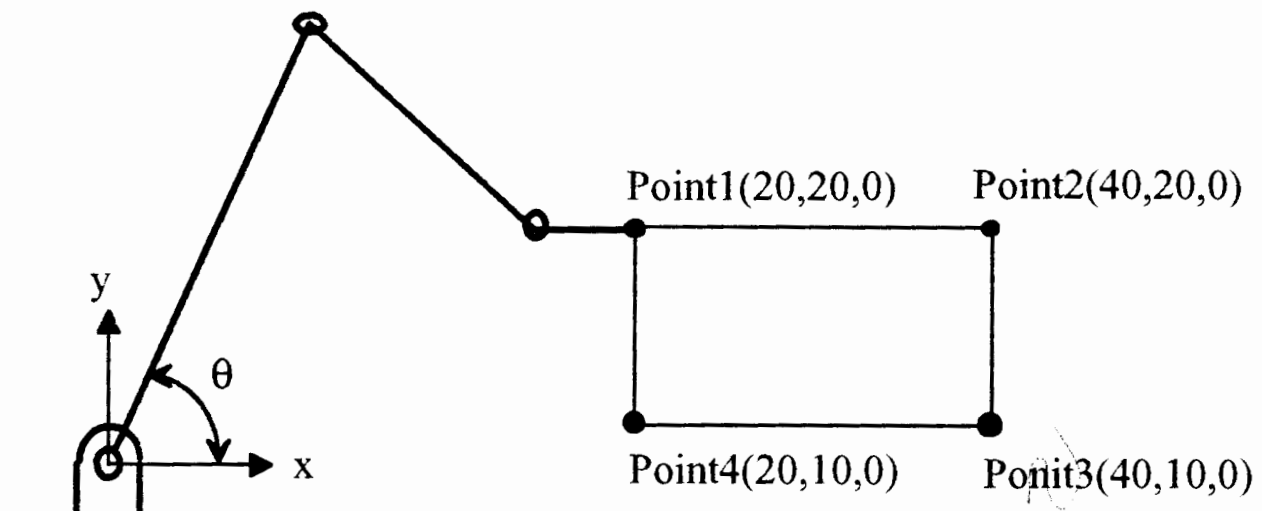

Figure 15. Configuration of Simulation in Point-to-Point Mode. 
TABLE X

\section{RESULTS FOR THE SIMULATION IN POINT-TO-POINT MODE WITH 10 LB PAYLOAD}

\begin{tabular}{|l|c|c|c|c|}
\hline \multicolumn{1}{|c|}{ (Unit: inch, degree) } & Ponit 1 & Point2 & Ponit3 & Ponit4 \\
\hline Desired X & 20.00 & 40.00 & 40.00 & 20.00 \\
\hline Achieved X with compensation & 20.00 & 40.00 & 40.00 & 20.00 \\
\hline Achieved X without compensation & 20.03 & 40.16 & 39.95 & 19.93 \\
\hline Desired Y & 20.00 & 20.00 & 10.00 & 10.00 \\
\hline Achieved Y with compensation & 20.00 & 20.00 & 10.00 & 10.00 \\
\hline Achieved Y without compensation & 19.61 & 19.16 & 9.26 & 9.79 \\
\hline Desired orientation $\theta$ & 0.00 & 0.00 & 0.00 & 0.00 \\
\hline Achieved orientation $\theta$ with compensation & 0.00 & 0.00 & 0.00 & 0.00 \\
\hline Achieved orientation $\theta$ without compensation & -1.15 & -1.65 & -1.53 & -0.83 \\
\hline
\end{tabular}

TABLE XI

\section{RESULTS FOR THE SIMULATION IN POINT-TO-POINT MODE WITH 20 LB PAYLOAD}

\begin{tabular}{|l|c|c|c|c|}
\hline \multicolumn{1}{|c|}{ (Unit: inch, degree) } & Ponit 1 & Point2 & Ponit3 & Ponit4 \\
\hline Desired X & 20.00 & 40.00 & 40.00 & 20.00 \\
\hline Achieved X with compensation & 20.00 & 40.00 & 40.00 & 20.00 \\
\hline Achieved X without compensation & 20.04 & 40.28 & 39.90 & 19.86 \\
\hline Desired Y & 20.00 & 20.00 & 10.00 & 10.00 \\
\hline Achieved Y with compensation & 20.00 & 20.00 & 10.00 & 10.00 \\
\hline Achieved Y without compensation & 19.26 & 18.44 & 8.64 & 9.62 \\
\hline Achieved orientation $\theta$ without compensation & 0.00 & 0.00 & 0.00 & 0.00 \\
\hline Achieved orientation $\theta$ with compensation & 0.00 & 0.00 & 0.00 & 0.00 \\
\hline Achieved orientation $\theta$ without compensation & -2.21 & -3.11 & -2.86 & -1.57 \\
\hline
\end{tabular}


links can be compensated.

The simulation then is performed in path mode. The trajectory of the end-effector is planned in straight line with uniform speed. The rigid manipulator with rigid control algorithm, the flexible manipulator without deflection compensation and the flexible manipulator with deflection compensation are simulated in the program. The accuracy requirement for the compensation loop is set as in equation (5.1). The simulation results are shown in Figure 16.

$$
\sqrt{\left(X_{a}-X_{d}\right)^{2}+\left(Y_{a}-Y_{d}\right)^{2}+\left(\theta_{a}-\theta_{d}\right)^{2}} \leq 10^{-4}
$$

where, $X_{a}, Y_{a}$ and $\theta_{a}$ are actual position and orientation of the end-effector;

$X_{d}, Y_{d}$ and $\theta_{d}$ are desired position and orientation of the end-effector.

In the path mode, the deflections at current configuration are used to approximate the deflections at next configuration in the path. These approximation of deflections are very close to the actual deflections since the change of the configuration between two consecutive path points does not cause significant changes of the deflections if these consecutive path points are close to each other. This is why the trajectories of the compensated manipulator are very close to the trajectories of the rigid manipulator as shown in Figure 16. Notice that the compensated flexible manipulator needs one more iteration to achieve the accuracy requirement set in the simulation program. 

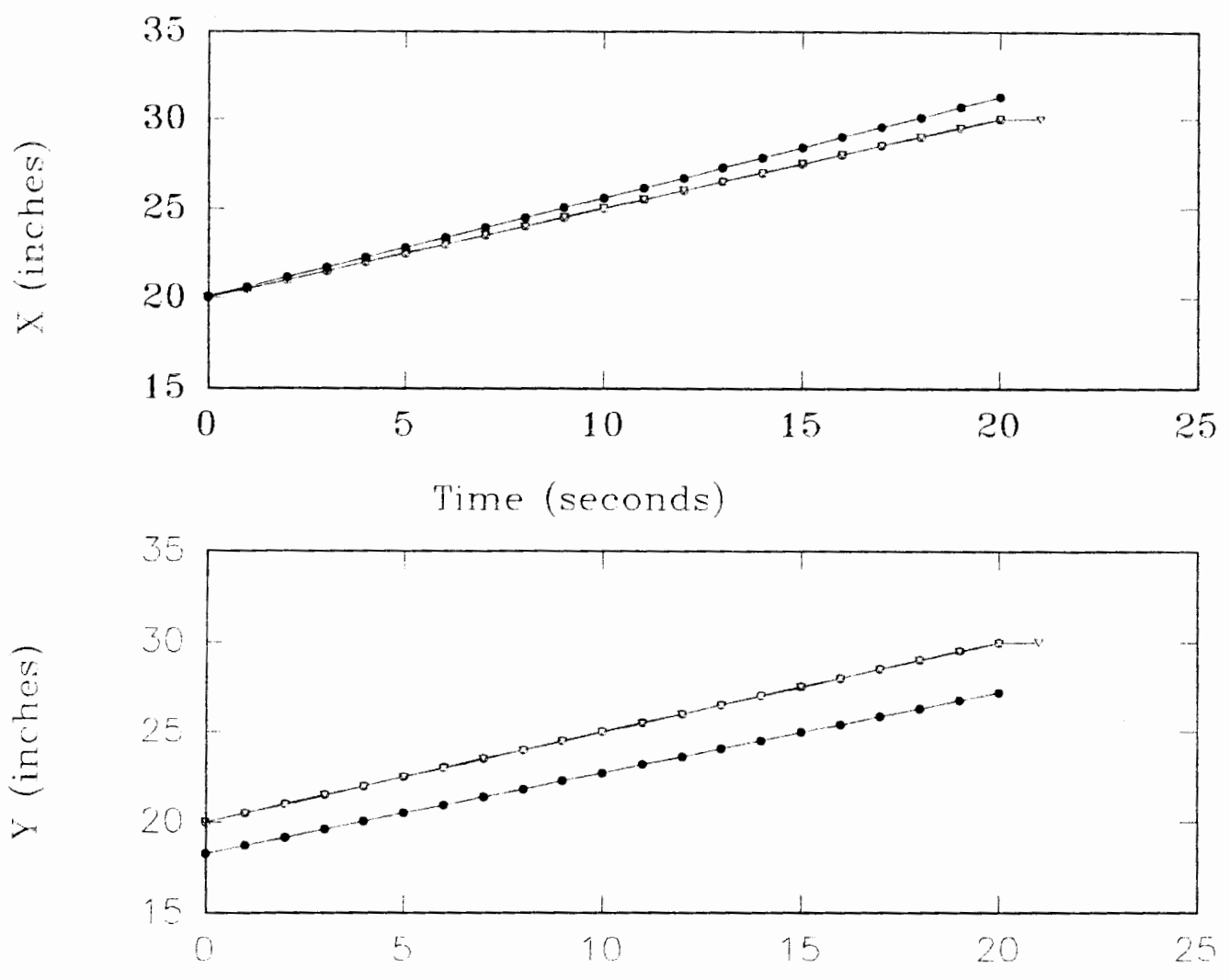

Time (seconds)

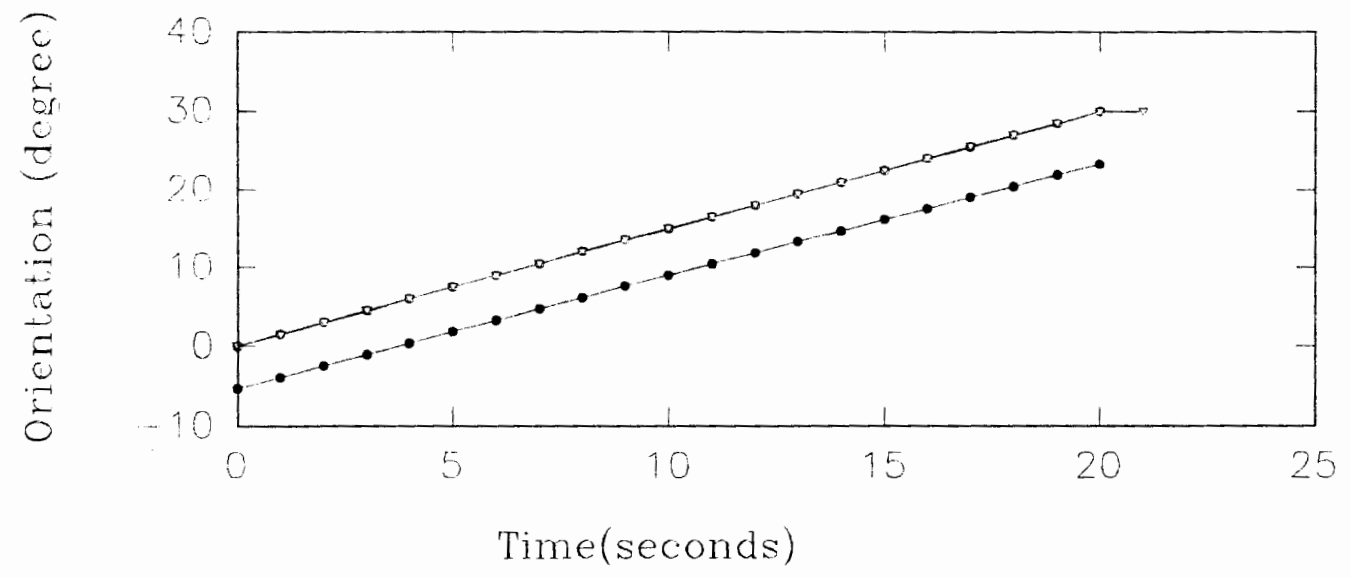

- Rigid Manipulator

Flexible Manipulator With Compensation

- Flexible Manipulator Without Ccompensation

Figure 16. Computer Simulation Results in Path Mode. 


\section{CHAPTER VI}

\section{EXPERIMENT ON}

\section{A MANIPULATOR WITH TWO FLEXIBLE LINKS}

\section{VI.1 INTRODUCTION}

The deflection compensation technique has been successfully simulated in computer in Chapter V. In order to proof the deflection compensation technique, a manipulator with two flexible links is built. The deflection detection technique using strain gages developed in Chapter II and the compensation algorithm developed in Chapter IV are verified experimentally. This chapter describes the experimental manipulator and presents the experimental results.

\section{VI.2 THE EXPERIMENTAL MANIPULATOR}

A planar manipulator with two flexible links is designed and built for the purpose of experimental verification of the deflection compensation technique. The manipulator is shown in Figure 17 and its schematic representation is shown in Figure 18. The design 


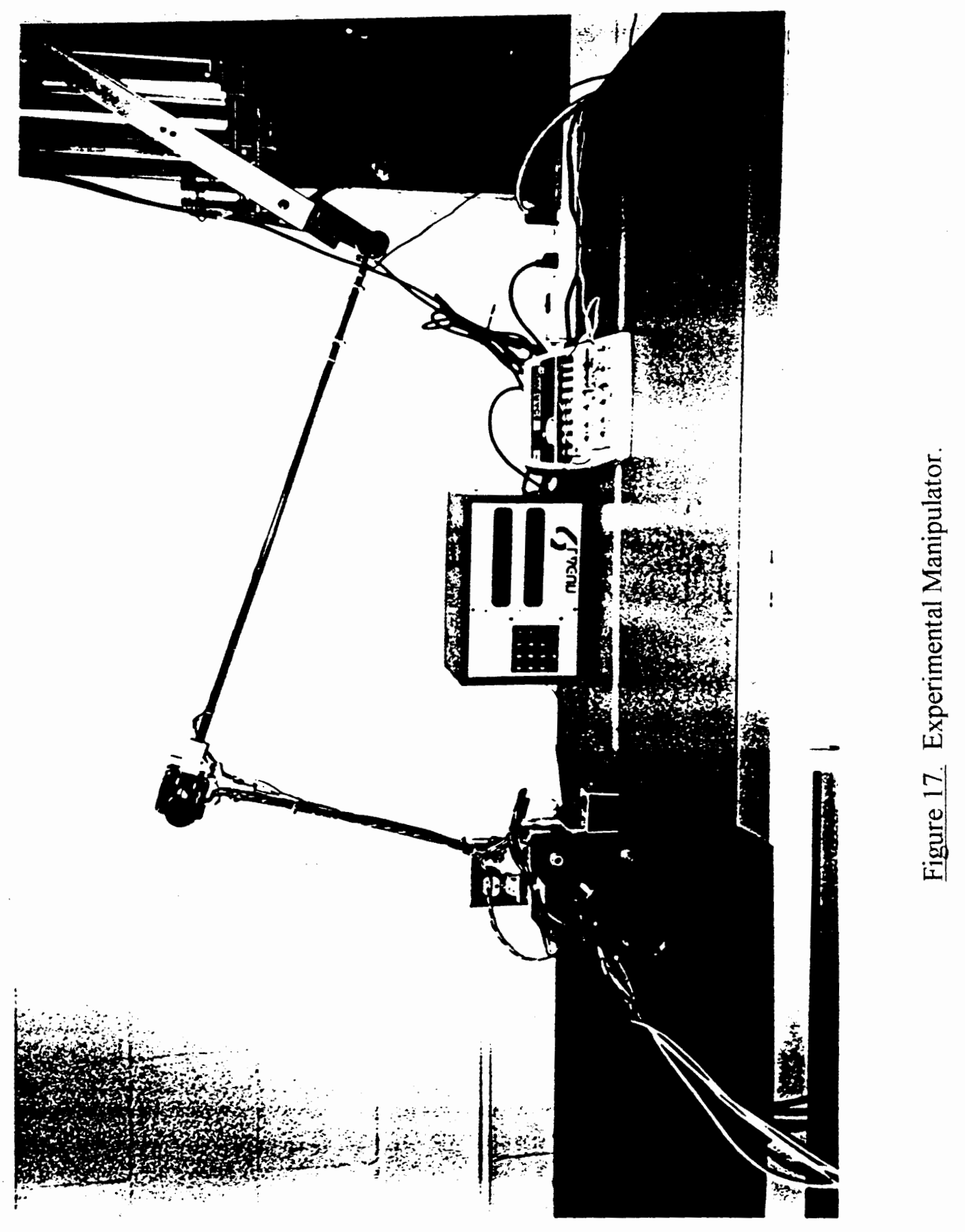




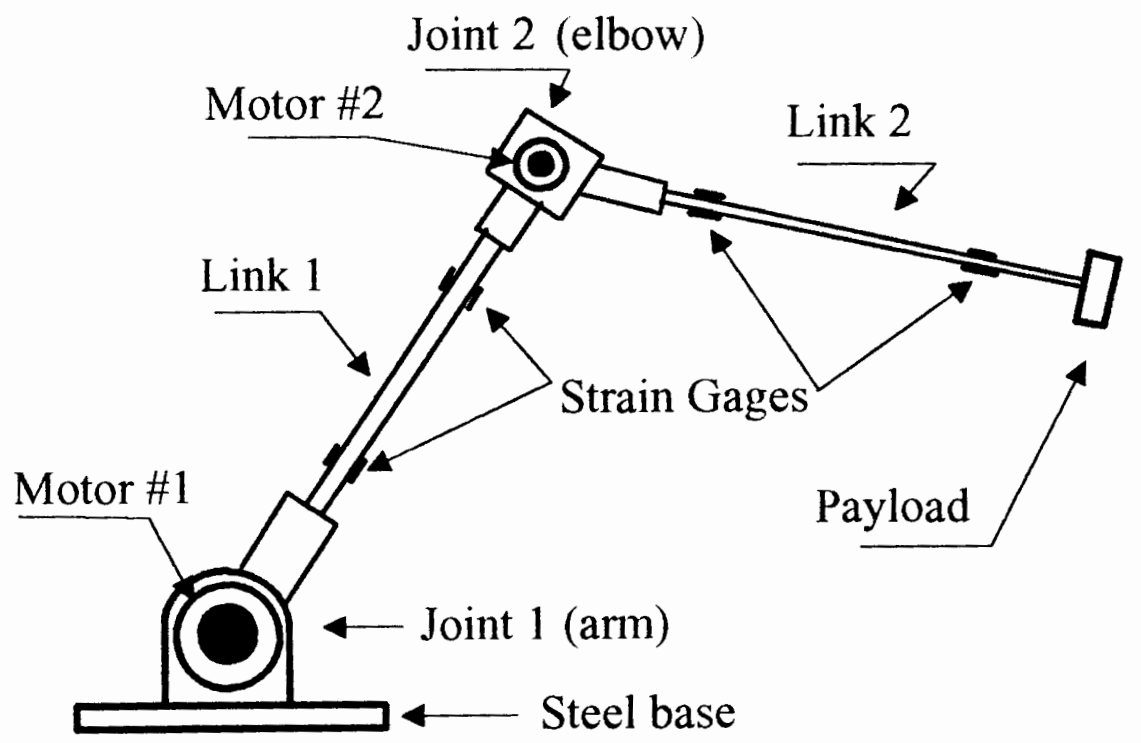

Figure 18. Schematic of the Experimental Manipulator. 
criteria of this manipulator are: (1) the joint positions can be controlled accurately, (2) the links have sufficient flexibility such that the accuracy improvement of the end-effector can be easily detected by available position measurement system without expensive calibration required, (3) the parts of the manipulator can be easily machined with available equipments, (4) the joints are relatively rigid with respect to the links, and (5) the flexible links are easily replaceble for further investigation of different links.

In order to satisfy the criteria, two actuators are directly mounted at the joints to eliminate the error introduced by transmission. The two links of the manipulator move within a vertical plane. The first link is an aluminum cylinder and the second link is a composite hollow cylinder.

The deflection detection technique developed in Chapter II is utilized to monitor the deflections. Two pairs of strain gages are installed on each link. The parameters of the strain-deflection model are obtained using the experimental identification method as tdescribed in Chapter III. The physical parameters and the constant Zs of the links are shown in Table XII and Table XIII.

TABLE XII

PARAMETERS OF LINK \#1 OF THE EXPERIMENTAL MANIPULATOR

\begin{tabular}{|c|c|c|c|c|c|c|}
\hline Length (inches) & $\mathrm{Z} 1$ & $\mathrm{Z} 2$ & $\mathrm{Z3}$ & $\mathrm{Z} 4$ & $\mathrm{Z} 5$ & $\mathrm{Z} 6$ \\
\hline 21.00 & 79.89 & 186.41 & 0.00 & 26.21 & 0.83 & 0.00 \\
\hline
\end{tabular}


TABLE XIII

PARAMETERS OF LINK \#2 OF

THE EXPERIMENTAL MANIPULATOR

\begin{tabular}{|c|c|c|c|c|c|c|}
\hline Length (inches) & $\mathrm{Z} 1$ & $\mathrm{Z} 2$ & $\mathrm{Z3}$ & $\mathrm{Z} 4$ & $\mathrm{Z} 5$ & $\mathrm{Z} 6$ \\
\hline 28.00 & 185.68 & 584.90 & 0.00 & 11.85 & 31.96 & 0.00 \\
\hline
\end{tabular}

The actuator used to drive the elbow is chosen to satisfy the torque requirement and as light as possible because it is directly mounted at the elbow. An E352 DC servo motor supplied by Electro-Craft is used to drive the elbow (Motor \#2). A gear box with 1:180 gear ratio is employed to obtain the torque requirement for joint $\# 2$. The weight of the actuator to drive the arm is not important, but this actuator requires large torque. An E652 DC servo motor supplied by Electro-Craft is used to drive the arm (Motor \#1). A gear box with 1:90 gear ratio is employed to obtain the torque requirement for joint \#1. Tachometers and optical encoders are mounted on the motors to detect the velocities and positions of the motors. The motors are powered by a MAX-100 pulse-width modulated (PWM) servo drivers. The velocity detected by the tachometer is fedback to the MAX-100 driver to complete the velocity control loop. The position detected by the optical encoder is decoded by a decoder and is fedback to the computer to complete the position control loop. The position resolution of the joint $\# 1$ is 0.01 degree. The position resolution of joint $\# 2$ is 0.005 degree. The functional diagram of the actuator control is shown in Figure 19. Table XIV and Table XV list the specifications of the actuator components. 


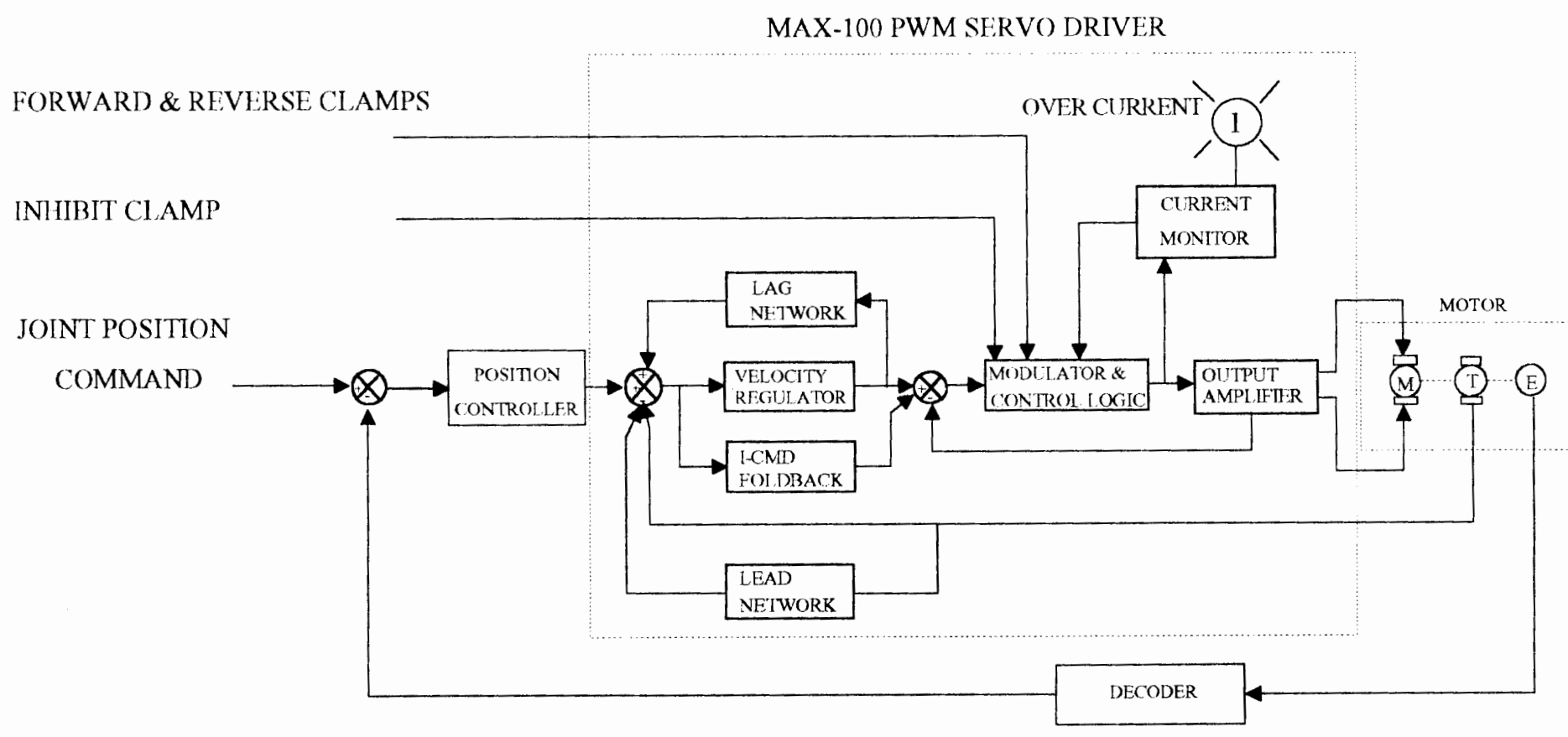

Figure 19. Functional Diagram of the Actuator Control. 
TABLE XIV

COMPONENTS OF ACTUATOR \#1

\begin{tabular}{|c|c|c|c|}
\hline COMPONENT & SUPPLIER & MODEL & DESCRIPTION \\
\hline Motor & Electro-Craft & E652 & $\begin{array}{c}\text { DC Servo motor } \\
\text { Max. torque: } 148 \mathrm{lb} \text {-in }\end{array}$ \\
\hline Tachometer & Electro-Craft & T501 & Tach. Voltage Const 14 V/krpm \\
\hline Gear box & Electro-Craft & G405 & $1: 90$ gear ratio \\
\hline Optical encoder & Renco Encoders & R80 & $\begin{array}{c}100 \text { lines, incremental } \\
\text { Sine wave model } \\
5 \text { VDC }+/-5 \%\end{array}$ \\
\hline Driver & Robbins \& Myers & MAX-100 & 25KHz pulse-width modulated \\
\hline
\end{tabular}

TABLE XV

COMPONENTS OF ACTUATOR \#2

\begin{tabular}{|c|c|c|c|}
\hline COMPONENT & SUPPLIER & MODEL & DESCRIPTION \\
\hline Motor & Electro-Craft & E352 & $\begin{array}{c}\text { DC Servo motor } \\
\text { Max. torque: } 15.5 \mathrm{lb}-\text { in }\end{array}$ \\
\hline Tachometer & Electro-Craft & T501 & Tach. Voltage Const 3.5 V/krpm \\
\hline Gear box & Electro-Craft & G405 & $1: 180$ gear ratio \\
\hline Optical encoder & Renco Encoders & R60 & $\begin{array}{c}100 \text { lines, incremental } \\
\text { Sine wave model } \\
5 \text { DVC }+/-5 \%\end{array}$ \\
\hline Driver & Robbins \& Myers & MAX-100 & 25KHz pulse-width modulated \\
\hline
\end{tabular}


Table XVI lists components of the data acquisition and control hardware. The strains are measured through a Model 2100 Strain Gage and Amplifier System supplied by Measurement Group, Inc. The 2100 Strain Gage and Amplifier System contains four channels and the amplifiers in the system. Each amplifier has the continuously adjustable gain from 1 to 2100 . The half bridge configuration is employed for the strain measurement. The Wheatstone bridge circuits are completed inside the 2100 Strain Gage and Amplifier System. The outputs of the strain gage system are read by the computer through the 16 bit $\mathrm{A} / \mathrm{D}$ converters in the AT-MIO-16X multifunction $\mathrm{I} / \mathrm{O}$ board supplied by National Instruments Corporation. The deflections are determined from the strains using the method described in Chapter II and Chapter III. The digital controller outputs are converted to voltages through the D/A converters in the AT-MIO-16X board, then the voltages are supplied to the MAX-100 amplifiers as velocity commands. The amplifiers take feedback form the motor tachometers to complete their own analog velocity servo loops. The only feedback variables used by the digital controllers are the angles of joint \#1 and joint \#2. These angles are measured by the optical encoders at the motors. The encoders have resolutions of 400 quadrature counts per revolution. The resolutions are enhanced by the gear trains in the boxes. In terms of the output shaft of joint \#1 the encoder has resolution of 3600 quadrature counts per revolution. In terms of the output shaft of joint \#2 the encoder has resolution of 7200 quadrature counts per revolution. The computer reads the angles of the joints through a DIO0168 decoder board supplied by OMEGA. The control computer is a 486 based IBM compatible computer. The control 
program and the control utilities (encoder reading, A/D conversion and D/A conversions etc.) are written in Turbo Pascal programming language.

TABLE XVI

DATA ACQUISITION AND CONTROL HARDWARE

\begin{tabular}{|l|c|c|l|}
\hline \multicolumn{1}{|c|}{ COMPONENT } & SUPPLIER & $\begin{array}{c}\text { PART } \\
\text { NUMBER }\end{array}$ & DESCRIPTION \\
\hline $\begin{array}{l}\text { 2100 Strain Gage } \\
\text { Conditioner and } \\
\text { Amplifier System }\end{array}$ & Measurements Group & & $\begin{array}{l}\text { Dynamic measurement } \\
\text { Bridge completion } \\
\text { Adjustable gain }\end{array}$ \\
\hline $\begin{array}{l}\text { AT-MIO-16X } \\
\text { Multifunction I/O } \\
\text { Board }\end{array}$ & National Instruments & $3220488-01$ & $\begin{array}{l}10 \text { channels A/D 16 bits } \\
2 \text { channels D/A 16 bits }\end{array}$ \\
\hline $\begin{array}{l}\text { SCXI-1140 } \\
\text { Sample \& Hold Module }\end{array}$ & National Instruments & $320410-01$ & $\begin{array}{l}10 \text { channels } \\
\text { Programmable gains }\end{array}$ \\
\hline $\begin{array}{l}\text { SCXI-1000/1001 } \\
\text { eXtensions Module }\end{array}$ & National Instruments & $320423-01$ & \\
\hline $\begin{array}{l}\text { Decoder Board } \\
\text { Omega }\end{array}$ & & $\begin{array}{l}\text { Decoder circuit } \\
\text { Cascadable counters to } \\
64 \text { bits }\end{array}$ \\
\hline
\end{tabular}

\section{VI.3 PATH PLANING OF THE JOINT ANGLES}

In this study, the vibration is not controlled because of the quasi-static assumption.

To minimize the vibration during the motion, it is desired for the motion of the manipulator to be as smooth as possible because jerky motions tend to cause more serious vibrations by exciting resonance in the manipulator. 
In order to obtain a smooth motion of the manipulator, the trajectory is planned in joint space using cubic polynomials [17]. The joints start moving from the initial position to the target position in smooth paths $\theta(\mathrm{t})$. Other than that the movements are synchronized, the determination of the desired joint angle function for one joint does not depend on the function for the other joint. The target angles of the each joint are solved using the inverse kinematics for given desired position of the end-effector. The deflection variables are approximated using the current deflections. Since the deflections of the links are configuration dependent, the target angles from the inverse kinematics generally will not match the desired joint angles. This errors will be corrected by the iteration described in the control algorithm in Chapter IV.

To make a smooth motion, four constrains for the function $\theta(\mathrm{t})$ are required. Two constrains are from the position requirement as equations (6.1) and (6.2). Othe two constrains are from the velocity requirement as equations (6.3) and (6.4).

$$
\begin{aligned}
& \theta(0)=\theta_{0} \\
& \theta(T)=\theta_{f} \\
& \dot{\theta}(0)=0 \\
& \dot{\theta}(T)=0
\end{aligned}
$$

where $\mathrm{T}$ is the planed traveling time.

These four constrains can be satisfied by a cubic polynomial. A cubic polynomial has the form shown in equation (6.5).

$$
\theta(t)=a_{0}+a_{1} \times t+a_{2} \times t^{2}+a_{3} \times t^{3}
$$


By substituting the four constrains to the cubic polynomial, the constants, $a_{0}, a_{1}, a_{2}$ and $a_{3}$ are obtained as in equations (6.7) through (6.10).

$$
\begin{aligned}
& a_{0}=\theta_{0} \\
& a_{1}=0 \\
& a_{2}=\frac{3}{T^{2}} \times\left(\theta_{f}-\theta_{0}\right) \\
& a_{3}=\frac{2}{T^{3}} \times\left(\theta_{f}-\theta_{0}\right)
\end{aligned}
$$

The resulting position, velocity and acceleration profiles are shown in Figure 20. Once the target position and orientation of the end-effector are input, the system will generate the trajectories at run time for two joints according to the cubic polynomials discussed above.

\section{VI.4 EXPERIMENT ON JOINT SPACE CONTROL}

To verify the compensation control algorithm, the joint angle positions must be controlled accurately. This section presents the results of investigation on joint position control. The cubic trajectory planning for the joint angles described in last section is employed. The proportional control is used for the joint position controllers.

Figure 21 shows the controlled trajectories for joint \#1 with the position controller gains 2,16 and 32 . The response shows a typical 2 nd order type dynamics system 

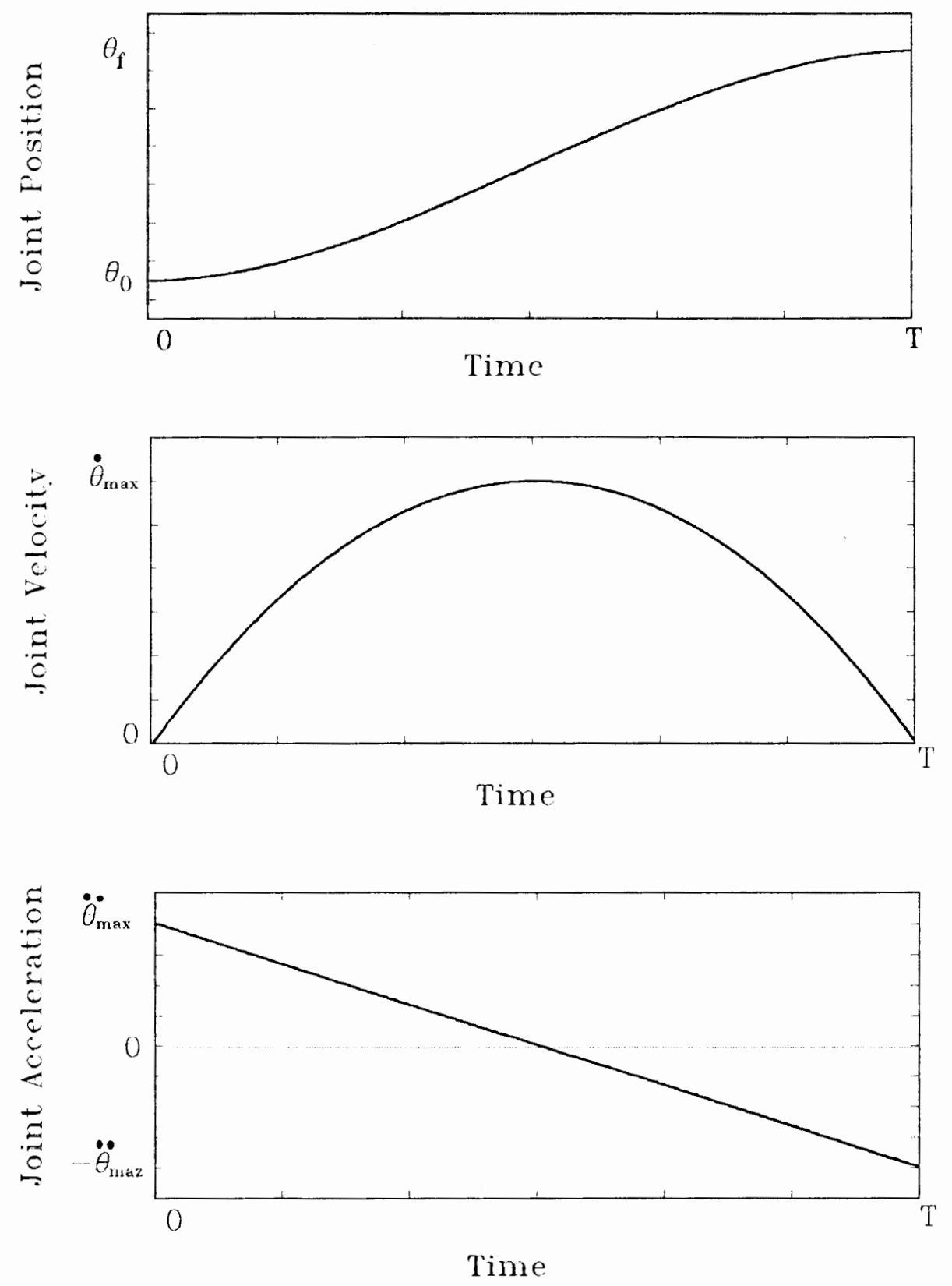

Figure 20. Joint Trajectory Planning with Cubic Polynomial. 


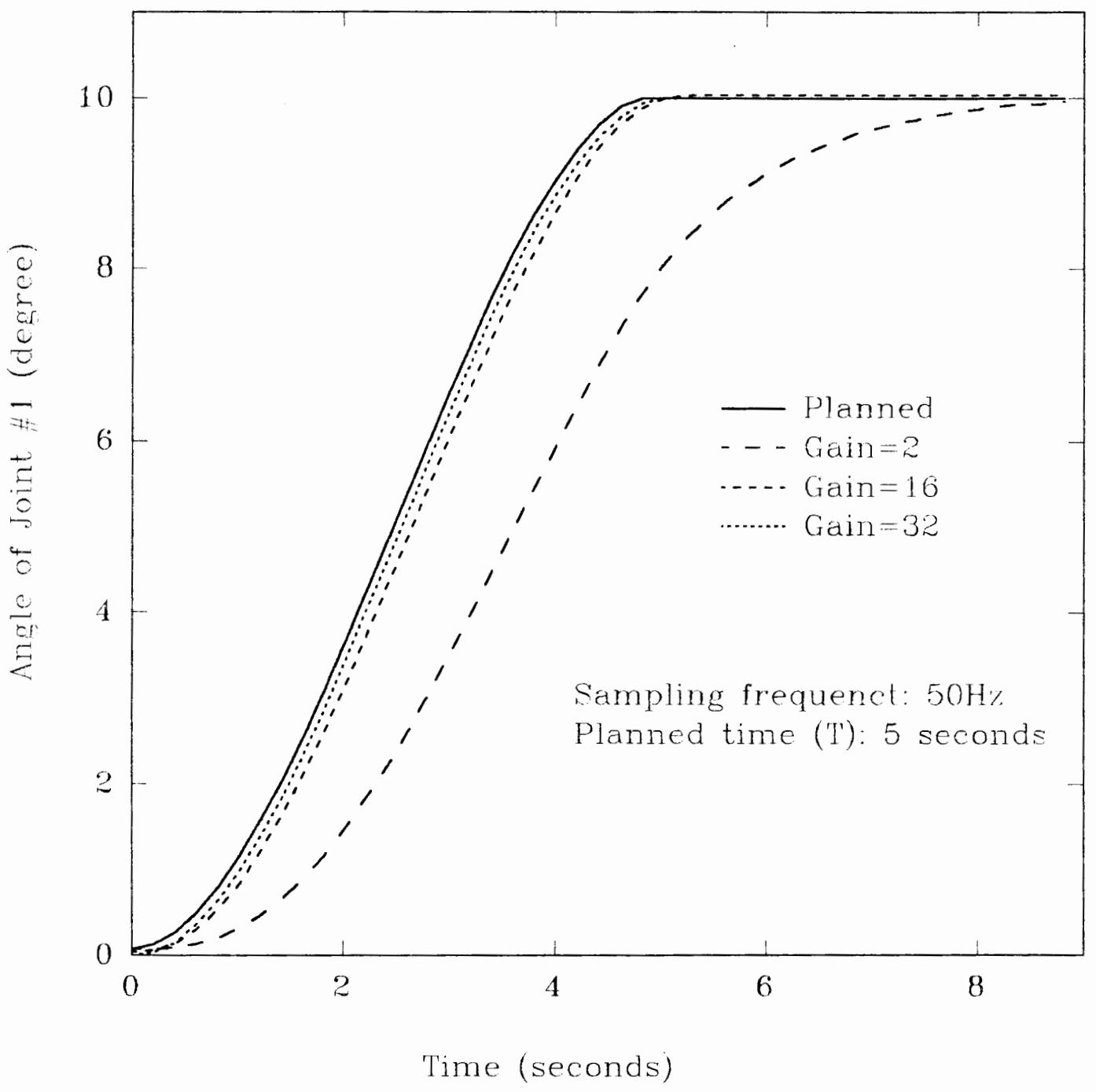

Figure 21. Experimental Results of Joint Space Control for Joint \#1 at Gain=2, 16, 32. 
response as expected. The initial joint angle is at 0 degree and the target angle is 10 degree. The sampling frequency is $50 \mathrm{~Hz}$. The planned traveling time $\mathrm{T}$ is 5 seconds.

It can be seen in Figure 21 that the actual obtained trajectories are moving close to the planned trajectory and the steady state errors decrease as the gain increased. The joint motion dose not show oscillation until the gain is increased to 256 .

Figure 22 shows the controlled trajectories for joint $\# 2$ with the position controller gains 2,16 and 32 . The initial angle is at 0 degree and the target angle is 10 degree with 5 seconds planned traveling time $\mathrm{T}$. The sampling frequency is $50 \mathrm{~Hz}$. It can be seen that the actual obtained trajectories are moving close to the planned trajectory and the steady state errors decrease as the gain increased. The joint motion does not show oscillation until the gain is increased to 32 . The motion starts to oscillate when the gain equals to 32 . As the gain is increased further, the oscillation become more serious. Figure 23 shows the actual obtained trajectory with the gain $(\mathrm{Kp})$ equals to 160 . It can be seen that the motion oscillates seriously at this gain.

It should be noted that the position of the joints are observed from the optical encoders directly mounted on the shafts of the motors. The actual positions of the joints are different from the observed position because the nonlinearities of the gear boxes.

From the results of the investigations, the gain ( $\mathrm{kp}$ ) for joint \#1 is chosen to be 64 and the gain (Kp) for joint $\# 2$ is chosen to be 30 . To investigate the effects of sampling frequency, the sampling frequency is decreased with these gains which provide the smooth motions at $50 \mathrm{~Hz}$ sampling frequency. The motions become oscillatory when the sampling frequency is decreased to $30 \mathrm{~Hz}$. The motions show no difference as the sampling 


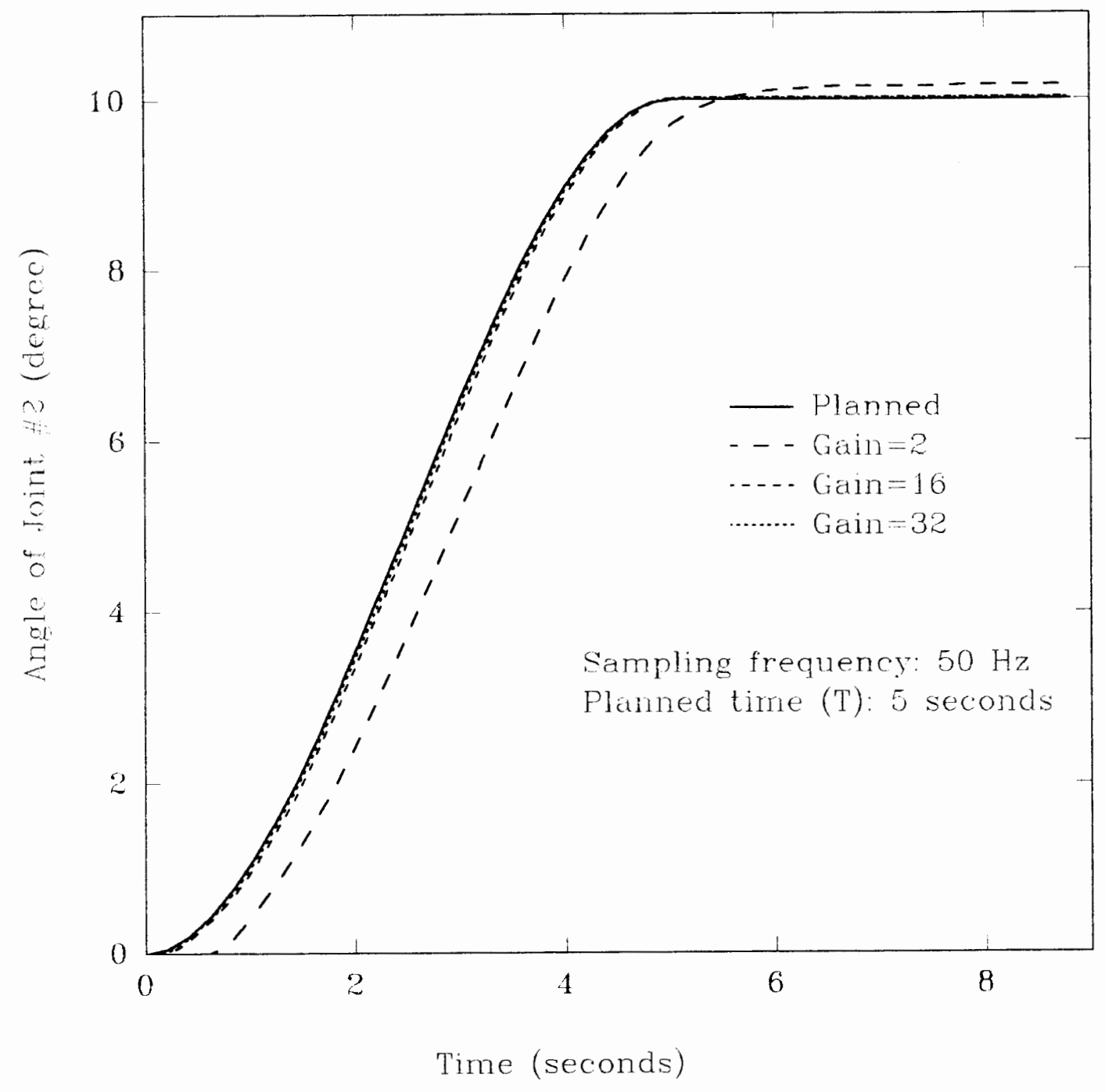

Figure 22. Experimental Results of Joint Space Control for Joint \#2 at Gain=2, 16, 32. 


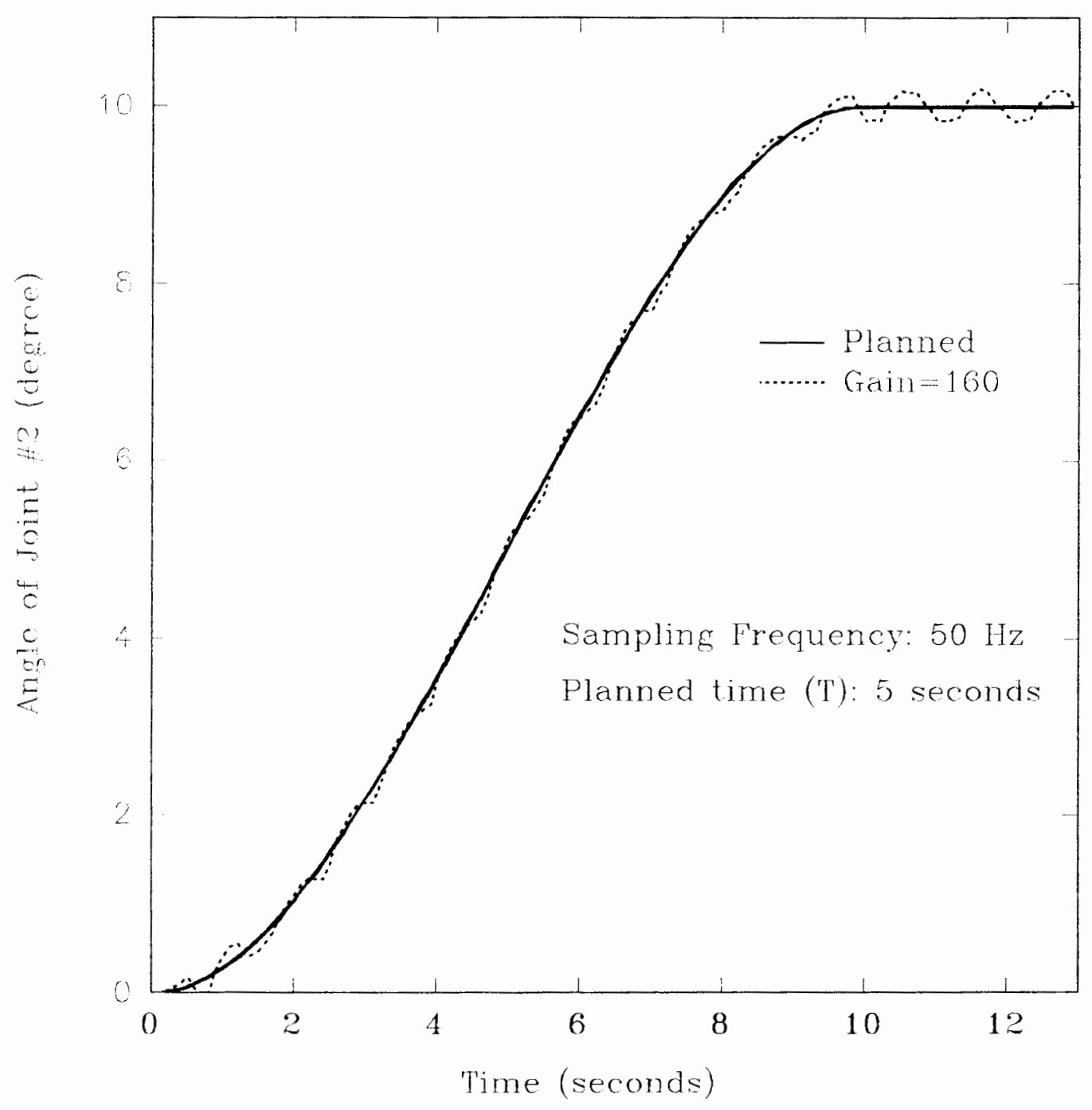

Figure 23 Experimental Results of Joint Space Control for Joint $\# 2$ at Gain $=160$. 
frequency increased beyond $50 \mathrm{~Hz}$. For the experiment in this work, $100 \mathrm{~Hz}$ sampling frequency is used.

\section{VI.5 EXPERIMENT ON}

\section{DEFLECTION COMPENSATION CONTROL}

The deflection compensation algorithm is successfully simulated in a computer in Chapter V. In last section, It has also been shown experimentally that the joint positions can be controlled accurately with appropriate gains and sampling frequency. Now the deflection compensation control algorithm is employed to control the experimental manipulator which has been built for this purpose. This section presents experimental procedures and the results of the experiment.

The manipulator carries a payload with unknown weight at its end. The motions of the manipulator are controlled in joint space as described in Sections VI.3 and Section VI.4. The average rotation speeds of the joints are kept as slow as 5 degree per second to simulate the quasi-static condition. The experimental manipulator is rest at initial position and then is commanded to a target point. The control algorithm based on the rigid-body assumption is first used to control the manipulator, then the compensation control algorithm developed in previous chapters is used to control the manipulator for same target point. The actual obtained position of the end-effector is measured by the $\mathrm{X}-\mathrm{Y}$ linear measurement system described in Chapter III and the result is recorded. This experiment is repeated for four different targets as shown in Figure 24. 


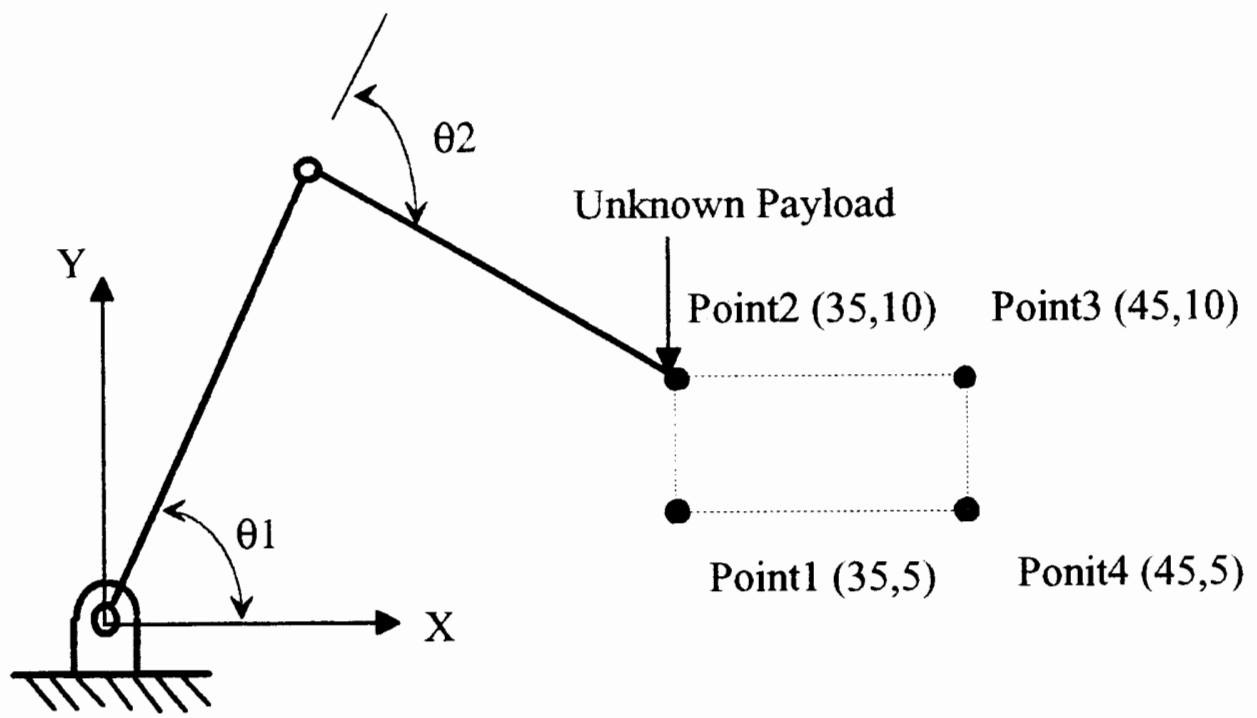

Figure 24. Experiments on the Two-link Manipulator. 
The results are presented in Table XVII, XVIII, XIX AND XX.

TABLE XVII

EXPERIMENTAL RESULT ON THE TWO-LINK MANIPULATOR FOR POINT \#1

\begin{tabular}{|l|c|c|c|c|}
\hline & $\mathrm{X}$ (inches) & $\mathrm{Y}$ (inches) & $\theta 1$ (degrees) & $\theta 2$ (degrees) \\
\hline Desired Position & 35.00 & 5.00 & & \\
\hline Using Rigid-body Algorithm & 34.34 & 3.85 & 59.12 & -87.38 \\
\hline Using Compensated Algorithm & 34.66 & 4.77 & 59.57 & -85.95 \\
\hline
\end{tabular}

TABLE XVIII

EXPERIMENTAL RESULT ON THE TWO-LINK MANIPULATOR FOR POINT \#2

\begin{tabular}{|l|c|c|c|c|}
\hline & $X$ (inches) & $Y$ (inches) & $\theta 1$ (degrees) & $\theta 2$ (degrees) \\
\hline Desired Position & 35.00 & 10.00 & & \\
\hline Using Rigid-body Algorithm & 34.47 & 8.90 & 64.61 & -83.65 \\
\hline Using Compensated Algorithm & 34.65 & 9.88 & 65.06 & -82.10 \\
\hline
\end{tabular}

TABLE XIX

EXPERIMENTAL RESULT ON THE TWO-LINK MANIPULATOR FOR POINT \#3

\begin{tabular}{|l|c|c|c|c|}
\hline & $X$ (inches) & $Y$ (inches) & $\theta 1$ (degrees) & $\theta 2$ (degrees) \\
\hline Desired Position & 45.00 & 10.00 & & \\
\hline Using Rigid-body Algorithm & 44.07 & 8.42 & 33.34 & -36.56 \\
\hline Using Compensated Algorithm & 45.00 & 9.65 & 34.05 & -34.98 \\
\hline
\end{tabular}


TABLE XX

EXPERIMENTAL RESULT ON THE TWO-LINK

MANIPULATOR FOR POINT \#4

\begin{tabular}{|l|c|c|c|c|}
\hline & $X$ (inches) & $Y$ (inches) & $\theta 1$ (degrees) & $\theta 2$ (degrees) \\
\hline Desired Position & 45.00 & 5.00 & & \\
\hline Using Rigid-body Algorithm & 44.76 & 3.38 & 30.52 & -42.41 \\
\hline Using Compensated Algorithm & 44.90 & 4.71 & 31.24 & -40.83 \\
\hline
\end{tabular}

As shown in the experimental results, the compensation control improves the positioning accuracy of the flexible manipulator significantly. In this experiment the geometry and the elastic properties of the two links as well as payload are unknown.

It is noted from the experimental results that there are errors between the desired targets and actually attained positions. The errors are due to the inaccuracies of the calibrations of the manipulator, noise involved in the strain measurement and the inaccuracy of the joint angle control. These error sources need to be eliminated in order to verify the deflection compensation technique in greater accuracy level. 


\section{CHAPTER VII}

\section{SUMMARY}

A approach to compensate the structure deflections of a manipulator is investigated in this work. The quasi-static condition is assumed. In this approach, strain gages are used to monitor the elastic reaction of the flexible links due to the own weight of the manipulator and the unknown payload. The deflections are compensated by a control algorithm. Although this approach is designed to work for the general loading conditions, only the bending deflection in a plane is investigated in detail. The deflection compensation control is both verified in computer simulations and experiments.

A mathematical model relating the strains to the deflections is developed based on Castigliano's theorem of least work. The general loading conditions of a flexible link are studied. The strain-deflection model is carried out for the planar bending deflection in detail. It is found that minimum two strain gages per link are needed to monitor the bending deflection in a plane. The parameters of the strain-deflection model can be obtained theoretically for the links with known geometry and elastic properties. They also can be obtained experimentally using identification method without knowing the geometry and elastic properties of the flexible link. This has a great advantage to the applications where the manipulator links have complex shapes and/or the elastic properties of the links are unknown. Once the parameters of the strain-deflection model are obtained, the 
deflection of the flexible link can be detected without knowing the exact payload. This gives a great flexibility to the applications where the payloads very from task to task. A experiment is setup to verify this deflection-detection method. The experimental results show that the deflection of a flexible link can be monitored rather accurately using this approach.

The deflection's information is used as feedback to compensated the deflections on real-time. A deflection compensation control algorithm is developed. The deflections of the manipulator's links are included in the kinematics model as variables. For the real-time control of manipulator, a closed-form inverse kinematics is very useful. As an example, the inverse kinematics including the deflections as variables is solved in closed-form for a planar manipulator with three degrees-of-freedom. Because the deflections of individual links are dependent on the configuration of the manipulator and the payload, the deflections of the links are unknown ahead of time. The deflections at the current configuration are used to approximate the deflections at final configuration for the iteration. This deflection compensation control algorithm is simulated in a computer for a planar manipulator with three degrees of freedom. The simulation results show that the algorithm has a good convergence.

A two-link planar manipulator with flexible links is built for the purpose of experimental verification of the deflection compensation technique. The deflections of two flexible links are monitored by strain gages and deflection compensation algorithm is utilized to control the manipulator. The experimental results show significant improvement of the accuracy of the end-effector. 
From the experimental results, it is noted that there are still errors between the desired targets and the actual obtained positions even though the accuracy of the end-effector is improved significantly. One of the major error sources is the inaccuracy of calibration. For the open-loop manipulators, the accuracy of the end-effector is especially sensitive to the calibrations both for the joint angles and the origin of the coordinate, hence they should be calibrated very carefully. Unfortunately, the accurate calibrations require precise measurement devices. The calibrations need to improve further to study the deflection compensation control in greater accuracy level. Other major error sources include the noise involved with the strain measurement and inaccuracy of the joint actuator control.

One of the characteristics of the manipulators is the large torque requirement of the actuators. To achieve such large torque, speed reducers are used. For the experiment in this work, two traditional gear boxes with 1:90 and 1:180 gear ratio are employed. The gear boxes exhibit serious nonlinearity. This kind of nonlinearity is very difficult to controlled. The optical encoders that feed back the positions of the joint angles are mounted before the gear boxes. The nonliearitiy of the gear boxes cause errors in the position control of the joint angles.

Other than the error sources mentioned above can be improved to study this deflection compensation control technique further. One immediate extension of this work could be investigations of other links with different shapes and different materials. The two-link manipulator has been designed so that the links can be replaced easily. Another 
possible extension of this work is to monitoring not only the bending deflection but also the torsional deflection.

This work has focused on the quasi-static deflection effects of the manipulator links. Other problems with the light-weight manipulator have been experienced during the process of the experiment. As studied by many researchers, the experiment of the flexible manipulator again shows the serious vibration problem with the light-weight manipulator. Even though the joint motions are very slow and planned carefully in this experiment. There are many issues that will need to be resolved in order to use the light-weight manipulators practically [18]. The purpose of this study is to develop a systematic method to monitor and compensate the structure deflections of the flexible manipulator in order to support other developments in other issues of light-weight manipulators. 


\section{REFERENCES}

[1] J. N. Lygours, B. G. Mertzios, and N. C. Voulgaris, "Design and construction of a microcomputer-controlled light-weight robot arm", Robotics and autonomous systems, Vol 7, Number 4, November 1991.

[2] C. H. An, C. G. Atkeson, and J. M. Hollerbach, "Model-Based Control of a Robot Manipulator", The MIT Press, 1988.

[3] D. H. Kim, K. H. Cook, and J. H. Oh, "Identification and compensation of robot kinematic parameter for position accuracy improvement", Robotica, Vol 9, 1991, pp.99-105.

[4] T. A. G. Heeren, and F. E. Veldpaus, "An Optical System to Measure the End Effecttor Position for On-line Control Purposes", The International journal of Robotics Research, Vol 11, Number 1, February 1992, pp.53-63.

[5] A.J.Koivo and K.S.Lee, "Self-Tuning Control of a 7wo-Link Manipulator With a Flexible Forearm", The International Journal of Robotics Research, Vol. 11, No.4, August 1992, pp.383-395.

[6] A. Meghdari, "A variational approach for modeling flexibility effects in manipulator arms", Robotica, Vol 9, 1991, pp.213-217.

[7] B. Jonker, "A Finite Element Dynamic Analysis of Flexible Manipulators", The international Journal of Robotics Research, Vol 9, Number 4, August 1990, pp.59-74 (published by the MIT press)

[8] L. W. Chang, and J. F. Hamilton, "The Kinematics of Robotic Manipulators with Flexible Links Using an Equivalent Rigid Link System(ERLS) Model", ASME Journal of Dynamic systems, measurement, and Control , Vol.113, March 1991, pp.48-52.

[9] D. Williams and D. Turcic, "An Inverse Kinematic Analysis Procedure for Flexible Open-loop Mechanisms", Mech. Mach. Theory Vol. 27, No. 6, 1992, pp.701-714. 
[10] H. Kanoh, "Distributed Parameter Model of Flexible Robot Arms", Advanced Robotics, The International Journal of the Robotics Society of Japan, Vol.5, number 1, 1991, pp.87-99.

[11] Denavit,J., and Hartenberg,R.S., "A Kinematic Notation for Lower-Pair Mechanisim Base on Matrices." ASME Journal of Applied Mechanics, June 1955, pp.215-167.

[12] J. Yao, "Accuracy improvement: Modeling of elastic deflection", Robotica, Vol 9, 1991, pp.327-333.

[13] P. T. Anthony, and S. Yurkovich, "Application and Comparison of On-Line Identification Methods for Flexible Manipulator Control", The International Journal of Robotics Research, Vol 10, Number 5, October 1991, pp.515-527.

[14] P-3500 Instruction Manual, Measurements Group, Inc., 1991.

[15] SB-10 Instruction Manual, Measurements Group, Inc., 1991.

[16] T. Yoshikawa, "Foundation of Robotics Analysis and Control", The MIT Press, 1990 , pp. 52.

[17] J. Craig, "Introduction To Robotics, Mechanics and Control", Second Edition, Addison-Wesley Publishing Conpany, 1989.

[18] D. Williams, Phd. Thesis, "Finete Element Based Dyniamicical Modeling of Flexible Open-Loop Manipulator with Experimental REsults", University of Wisconsin-Madson, 1990. 